Dear author,

Please note that changes made in the online proofing system will be added to the article before publication but are not reflected in this PDF.

We also ask that this file not be used for submitting corrections. 


\title{
Ni-Ti SMA bars behaviour under compression
}

\author{
Javier Pereiro-Barceló ${ }^{\mathrm{a}}$, José L. Bonet ${ }^{\mathrm{b}, *}$ \\ a Instituto de Ciencia y Tecnología del Hormigón (ICITECH), Universitat Politècnica de València, C/Vera unnumbered, Valencia 46022, Spain \\ ${ }^{\mathrm{b}}$ Instituto de Ciencia y Tecnología del Hormigón (ICITECH), Universitat Politècnica de València, Valencia 46022, Spain
}

\section{H I G H L I G H T S}

- Ni-Ti bars with low slenderness can present two instability points.

- Slender Ni-Ti bars show only one instability point.

- Instability in compression of $\mathrm{Ni}-\mathrm{Ti}$ bars depends on tension-compression asymmetry.

- The proposed model determines $\mathrm{Ni}-\mathrm{Ti}$ bars behavior with instability in compression.

- The proposed model is faster and more robust than a finite element model.

\section{A R T I C L E I N F O}

\section{Article history:}

Received 9 May 2017

Received in revised form 27 July 2017

Accepted 15 August 2017

Available online xxxx

\section{Keywords:}

Shape memory alloys

$\mathrm{Ni}-\mathrm{Ti}$

Constitutive model

Superelasticity

Instability of compressed reinforcements

\section{G R A P H I C A L A B S T R A C T}

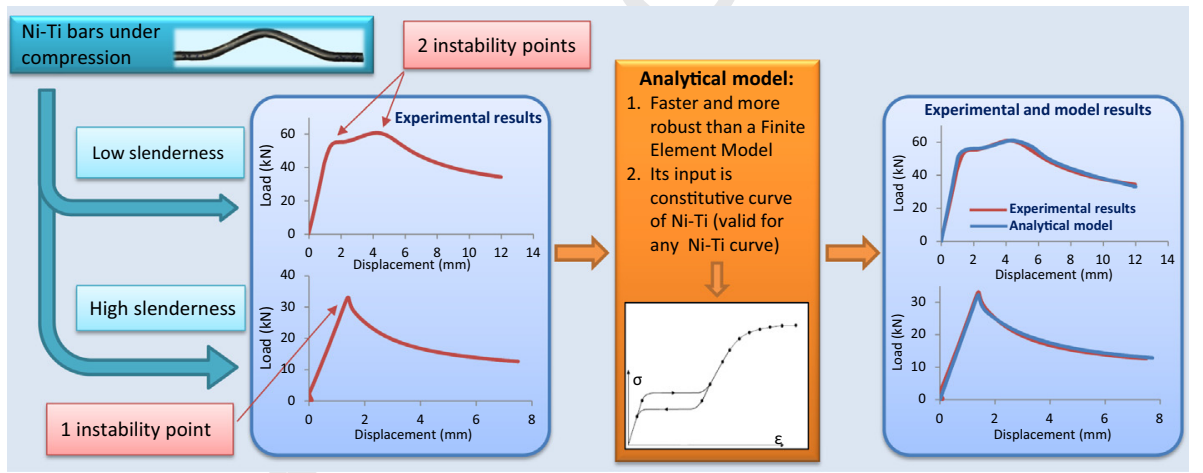

\section{A B S T R A C T}

SMA (Shape Memory Alloys) is a type of material suitable for using in civil engineering as concrete reinforcement because of their shape memory effect or superelasticity and their high ductility and damping capacity. However, Ni-Ti alloys Young modulus could be 3 or 4 times lower than steel (200 GPa) depending on the composition and thermal treatment, which can cause the instability of compressed bars. The main objective of this work is to provide a modified constitutive model of SMA bars, particularized for NiTi bars, that considers instability in compression. The inclusion of this effect in the constitutive equation allows for simulating Ni-Ti bars under compression in a simple way as if they were perfectly straight bars. To achieve this, six 12-mm diameter SMA bars made of Ni-Ti were tested under compression. The mechanical slendernesses of the six Ni-Ti samples were: $28.33,38,48,66,82$ and 108.33 . Thirty steel specimens were tested beforehand to validate the experimental setup and to calibrate the subsequent Abaqus finite element model. This model aims to conduct a parametric study to validate the proposed constitutive model of $\mathrm{Ni}$-Ti bars, including instability in compression.

(ㄷ) 2017 Elsevier Ltd. All rights reserved.

\section{Introduction}

Shape Memory Alloys (SMA) were discovered in 1932, but not until 30 years later did the first practical applications with SMA evolve. SMA is a material capable of undergoing considerable

\footnotetext{
* Corresponding author.

E-mail addresses: japebar@upv.es (J. Pereiro-Barceló), jlbonet@cst.upv.es (J.L. Bonet).
}

recoverable strains of $5-6 \%$ without displaying plastic strains. Its high durability, excellent dissipation capacity, high resistance to fatigue and its strain recovery capacity provide SMA material with numerous application possibilities in civil engineering [1-3], specifically in seismic design [4-7] and in prestressing and active confinement [8-14].

SMA has two different crystalline structures. The prevailing crystalline structure depends on temperature and the external stress applied. The high-temperature stable phase is known as 
austenite, while the low-temperature stable phase is known as martensite $[15,16]$. The mechanical behavior that makes these alloys unique is closely related with transformation between both phases. The shape memory effect (SME) and the superelastic effect are two exclusive properties of these materials. The former is the capacity to recover its original shape by heating, whereas the latter is the capacity to recover major strains after withdrawing the applied load [17].

According to DesRoches et al. [18], SMA made of Ni-Ti displays the SME below the martensitic transformation finalization temperature $M_{f}\left(T<M_{f}\right)$. Strains resulting from an applied external load are recovered by heating the material above austenitic transformation finalization temperature $A_{f}$. If $\mathrm{Ni}-\mathrm{Ti}$ is in the austenite phase $\left(M_{f}<A_{f}<T\right)$, martensite is generated when the material is submitted to a stress state, and the material reverts to austenite and recovers its original shape when the load is withdrawn. This effect is known as superelasticity. At an ever higher temperature (higher than $M_{d}$, which is the temperature at which the stress that causes martensite transformation is over the critical stress of permanent plastic strains), the material undergoes plastic strains under very high stress conditions.

Research literature includes models of the cyclic stress-strain behavior of SMA [19-24]. However, these models do not consider the instability due to compression in the SMA stress-strain relationship. This effect is particularly important for predicting the behavior of elements that undergo strong seismic action.

Modifications of a nonlinear cyclic stress-strain relationship, including instability due to compression, have been proposed in steel bars. It is worth highlighting the modifications of the Menegotto-Pinto cyclic stress-strain relationship $[25,26]$ by Gomes and Appleton [27], and by Dhakal and Maekawa [28]. Gomes and Appleton [27] proposed a stress-strain path based on the equilibrium of a plastic mechanism that took place after instability. Dhakal and Maekawa [28] put forward a constitutive equation of steel bars including instability due to compression, based on a finite element model. Massone and Moroder [29] proposed a steel model based on the plasticity concentration on plastic hinges capable of adding initial imperfection. Massone and López [30] extended aforementioned model by considering the effect of stirrups and concrete core expansion for bars inserted into a concrete section.

Several authors have reported experimental tests carried out with isolated steel bars submitted to compression loads: Mander [31], Mander [32], Monti and Nuti [33], Rodriguez et al. [34], Bayrak and Sheikh [35], Bae et al. [36]. The research literature on the behavior of SMA bars subjected to compression is much shorter than that on steel. Rahman et al. [37] and Rahmanand Tani [38] carried out a series of experimental tests on Ni-Ti bars, for different slenderness ratios, to study the instability under compression. They found that, unlike what happens in conventional materials like steel, for low slenderness ratios, Ni-Ti was capable of maintaining significantly high loads beyond the instability point, and could even increase the load capacity in some cases after going beyond a first instability point to then find a second instability point from which the load decreases. Similarly, Rahman and Tani [38] performed finite element analyses based on the large strain theory to predict the average stress and the equivalent strain curves of short Ni-Ti bars. Movchan et al. [39] and Movchan et al. [40] theoretically analyzed the instability in compression of SMA bars using the fraction volume concept of the martensitic phase. They concluded that the transformation of typical SMA phases affected the solution to the problem. Finally, Richter et al. [41] numerically analyzed the phenomenon so-called anti-buckling effect reported by Urushiyama et al. [42] in their experimental tests of Ni-Ti-Cu bars. This phenomenon takes place in bars in the martensitic phase that undergo uniaxial compression and sub- sequent bending. These authors attributed it to the constitution of different martensitic phases during the loading process. The model proposed by these authors is capable of representing this particular phenomenon in a pseudoelastic SMA regime.

The properties of $\mathrm{Ni}-\mathrm{Ti}$ (superelasticity and damping capacity) make it suitable to be used in concrete elements [2,43-45]. Therefore, a constitutive equation of SMA rebars that considers instability due to compression behavior, as it happens in steel reinforcements, enables the modelling of the reinforcement as a perfectly straight bar without having to consider a possible local imperfection of the bar in the model.

In view of the research literature, very few experimental studies have been conducted with isolated $\mathrm{Ni}$-Ti bars that undergo compression loads $[37,38]$. Besides, the studied diameter $(\phi=2 \mathrm{~mm})$ is shorter than that normally used as the compression reinforcement in concrete structures. Finally, there is no analytical or simplified model that can be used to calculate the constitutive equation in compression of the $\mathrm{Ni}$-Ti including instability due to compression.

Therefore, this paper proposes an analytical model for the calculation of the behavior of the bar which takes into account the instability in compression, that is to say, a model to get the average stress - equivalent strain relationship that includes buckling effects. It is noteworthy to mention that this average stress equivalent strain relationship takes into account structural aspects, and it is different from the fundamental stress-strain relationship of the material. In order to obtain the average stress - equivalent strain relationship, it is necessary to know beforehand the fundamental stress-strain behavior of the Ni-Ti as material, both in tension and in compression. To meet this objective, an experimental campaign was carried out with Ni-Ti bars. Then a finite element model was calibrated based on the experimental results to conduct and discuss a parametric study. Finally, an analytical model was proposed to modify the constitutive average stress - equivalent strain equation in compression of the $\mathrm{Ni}$ - $\mathrm{Ti}$ bars taking into account the instability. The results obtained with this model were then compared to those obtained with both the finite element model and experimental tests.

\section{Experimental program}

A series of six experimental tests were performed with $\mathrm{Ni}-\mathrm{Ti}$ bars subjected to compression. The obtained data were used to calibrate a numerical finite element model. Thirty steel bars were tested beforehand, for two reasons. Firstly, to validate the test configuration. To do so, the variation in the experimental results was analyzed and compared with the instability curve known as the "Column Research Council" (CRC) design curve [46]. Secondly, to have data to calibrate the independent finite element model parameters of the material stress-strain properties, like stiffness of certain boundary conditions (Section 3.1). The steel and Ni-Ti bars employed in the tests were $12-\mathrm{mm}$ in diameter.

\subsection{Material characterization}

In this section, the characteristics of $\mathrm{Ni}-\mathrm{Ti}$ and steel are described. In the case of $\mathrm{Ni}-\mathrm{Ti}$, three types of tests were conducted: simple stress-strain tests, compression tests and a Differential Scanning Calorimetry (DSC) test. A short Ni-Ti column, with a free length of $10 \mathrm{~mm}$, was tested in compression. This length is small enough so as to disregard the possible second order effects of the bar due to geometrical imperfections or to the application of the load. Finally, the steel bar was tested to obtain the stress-strain relationship according to standard UNE-EN ISO 6892-1 [47]. The 
constitutive curve obtained in this test is valid both for tension and for compression, due to the symmetrical behavior of steel.

The transformation temperatures have been obtained from the Differential Scanning Calorimetry (DSC) test (Fig. 1): $M_{f}=$ $-49.15^{\circ} \mathrm{C}, M_{s}=-31.23^{\circ} \mathrm{C}, A_{s}=-20.75^{\circ} \mathrm{C}$ and $A_{f}=-7.70{ }^{\circ} \mathrm{C}$.

Mechanical characteristics have been obtained by a direct tensile test at a room temperature of $27-30^{\circ} \mathrm{C}$ : Young's modulus under tension was $64647 \mathrm{MPa}$, the forward martensitic transformation under tension at room temperature began at a stress of $450 \mathrm{MPa}$. Unlike steel, Ni-Ti exhibited a different tension-compression behavior $[48,49]$. A compression test was conducted at a room temperature of $27-30^{\circ} \mathrm{C}$. The fundamental stress-strain curve of $\mathrm{Ni}$-Ti bars at room temperature under both tension and compression is shown in Fig. 2. Young modulus under compression was the same as in tension. The forward martensitic transformation under compression at room temperature also began at a stress of $450 \mathrm{MPa}$. The final martensitic transformation strain under compression at room temperature was $4.5 \%$, which coincided with a stress of $710 \mathrm{MPa}$. The martensitic modulus branch under compression at room temperature was $28125 \mathrm{MPa}$. The plastic branch started at a stress of $1150 \mathrm{MPa}$. Bars were supplied with a polished surface. According to Fig. 2a, the bars were not completely superlastic.

For the steel bar tests, steel with a high yield stress was employed and direct tensile tests were carried out. The Young modulus was $150400 \mathrm{MPa}$, the yield stress was $f_{y}=650 \mathrm{MPa}$, and the tangent modulus of the plastic branch was $32500 \mathrm{MPa}$. The surface was polished and non-corrugated.

\subsection{Test configuration}

Fig. 3 shows the configuration employed in the test. Each bar end was inserted into a replaceable case located in the center of a circular plate which was $120-\mathrm{mm}$ in diameter and $40-\mathrm{mm}$ in thickness. Each case was $30 \mathrm{~mm}$ deep to provide an effective fixing condition. Thus, the free length $L$ was calculated as $L=L_{\text {total }}-2 \cdot 30 \mathrm{~mm}$. Besides, each plate had a $1 \mathrm{~mm}$-diameter hole to let air out and, consequently, to improve the support conditions.

Table 1 shows the list of tests with the number of test specimens, the total bar length $L_{\text {total }}$, the free length of each test $L$ and mechanical slenderness $L / k$ (where $k=D / 4$ and $D$ is the bar diameter). A total of 30 steel bars and $6 \mathrm{Ni}$-Ti bars were tested.

The test was carried out in a universal IBERTEST hydraulic testing machine. This machine had two blocks between which specimens were placed with their support plates. The lower block was fixed and the upper block was mobile. The machine had a load cell, as well as two LVDTs to measure bar shortenings on the diametrically opposite ends to detect possible undesirable plate rotations.

A single loading-unloading cycle was run. Maximum strain took place between 30 and 60\%o depending on the specimen. After accomplishing the point of maximum displacement, the specimen was gradually unloaded at a constant speed until the load was approximately zero. The loading speed was $0.1 \mathrm{~mm} / \mathrm{min}$ in all the tests for both loading and unloading. A thermocouple was fitted in the central area of the Ni-Ti bars to control any changes in temperature that may be attributed to phase transformation.

\subsection{Discussion of experimental results}

To validate the proposed configuration of the tests, 30 steel bars were tested. Fig. 4 shows the stresses at instability points, which depend on slenderness $L / k$, which corresponds to the 30 steel bars. The fact that the results are scattered is expected, given the uncertainty of the imperfections. It is also expected that the instability load decreases with slenderness.

After the tests, deformations in the plate cases were found due to concentration of stresses, which indicated that fully fixed condition was not completely achieved. According to Euler's theory to elastic buckling: $\sigma_{\text {crit_Euler }}=\pi^{2} E I /\left[A(\alpha L)^{2}\right]$ where $E$ is the bar linear elasticity modulus (austenitic modulus), $I$ is its inertia moment, $L$ is its free fixed-fixed length, $A$ is the section area and $\alpha$ is the buckling factor. A $\alpha$ value of 0.57 was employed instead of 0.5 so as buckling load (for specimens which buckles in the elastic branch) was adjusted with the experiments. Consequently, free length of bars could be multiplied by $0.57 / 0.5$ to obtain the equivalent free length considering bars fully fixed. For this reason, results in Fig. 4 take into account the modified value of slenderness according the new free length. Fig. 4 also shows the "Column Research Council" (CRC) design curve [46], which considers material plasticity in the determination of the stress. The test configuration was validated despite the experimental results being scattered because

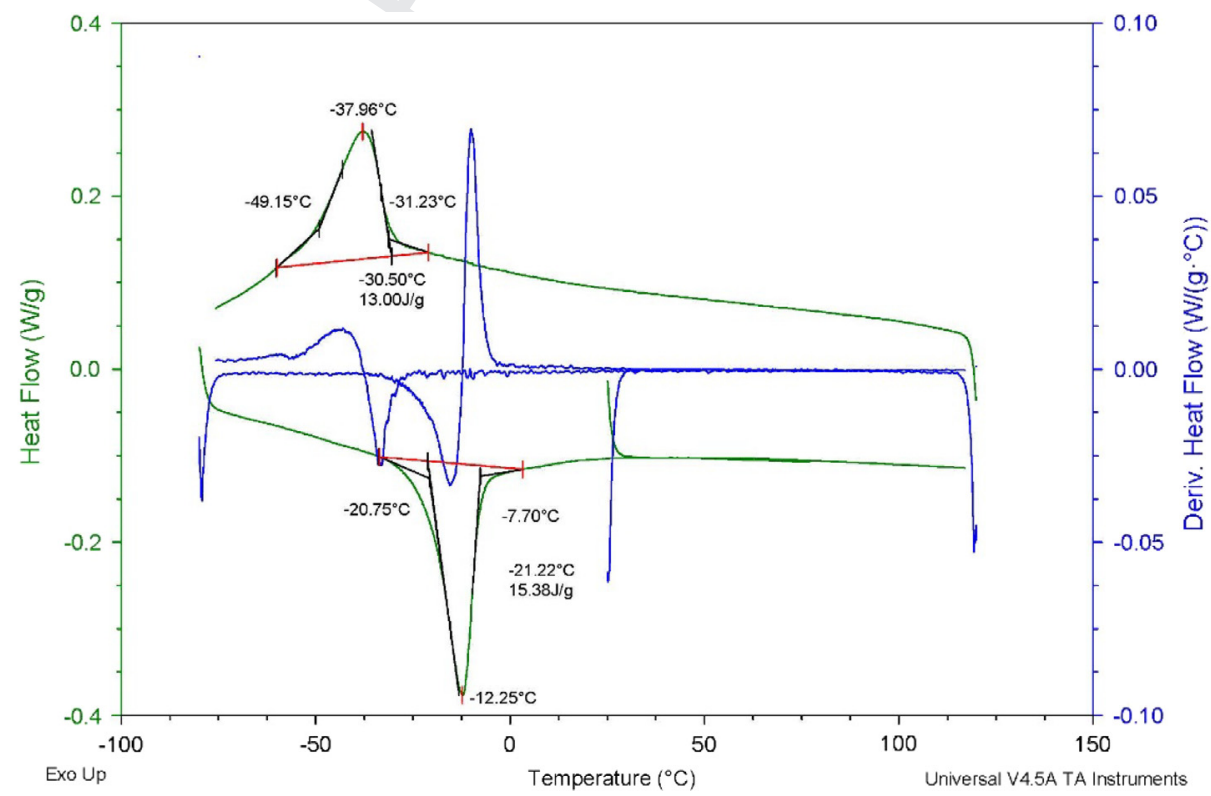

Fig. 1. Differential Scanning Calorimetry (DSC) test results. 


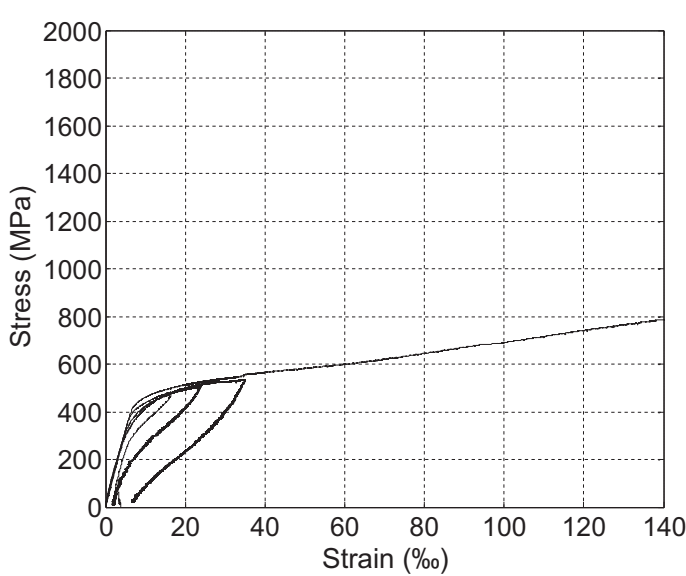

(a)

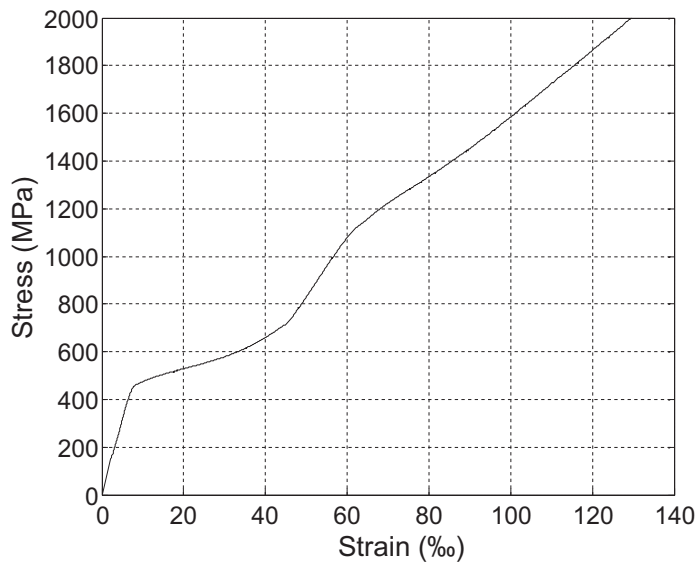

(b)

Fig. 2. Stress-strain diagram of Ni-Ti bars: (a) under tension; (b) under compression.

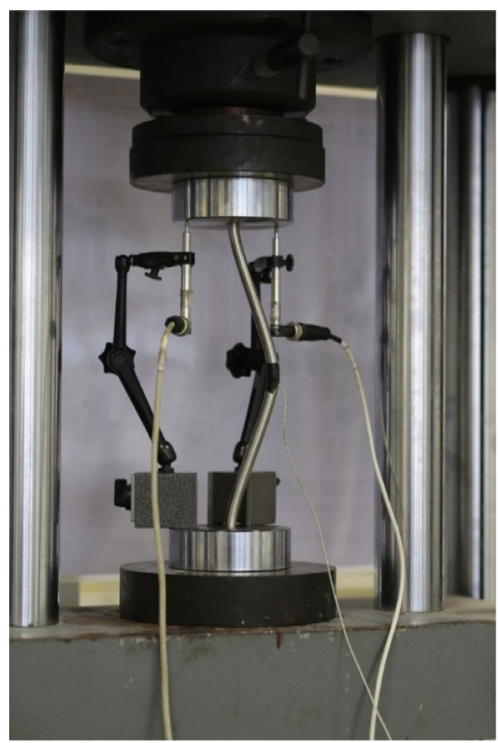

(a)

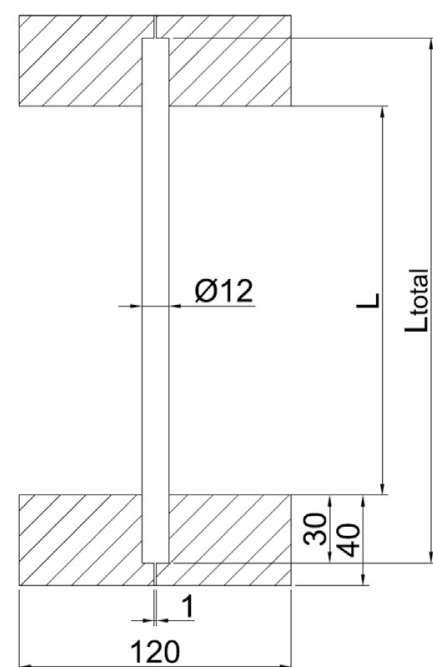

(b)

Fig. 3. Test configuration: (a) the outer configuration in tests; (b) test device measurements.

Table 1

Test specimens.

\begin{tabular}{|c|c|c|c|c|}
\hline Material & No. of specimens & Total bar length $L_{\text {total }}(\mathrm{mm})$ & Free length $L(\mathrm{~mm})$ & Slenderness $L / k$ \\
\hline \multirow{6}{*}{ Steel } & 3 & 133 & 73 & 24.33 \\
\hline & 4 & 174 & 114 & 38.00 \\
\hline & 4 & 205 & 145 & 48.33 \\
\hline & 2 & 252 & 192 & 64.00 \\
\hline & 2 & 306 & 246 & 82.00 \\
\hline & 3 & 342 & 282 & 94.00 \\
\hline \multirow[t]{6}{*}{ SMA } & 1 & 145 & 84 & 28.33 \\
\hline & 1 & 174 & 114 & 38.00 \\
\hline & 1 & 204 & 144 & 48.00 \\
\hline & 1 & 258 & 198 & 66.00 \\
\hline & 1 & 306 & 246 & 82.00 \\
\hline & 1 & 385 & 325 & 108.33 \\
\hline
\end{tabular}

Please cite this article in press as: J. Pereiro-Barceló, J.L. Bonet, Ni-Ti SMA bars behaviour under compression, Constr. Build. Mater. (2017), http://dx.doi. 


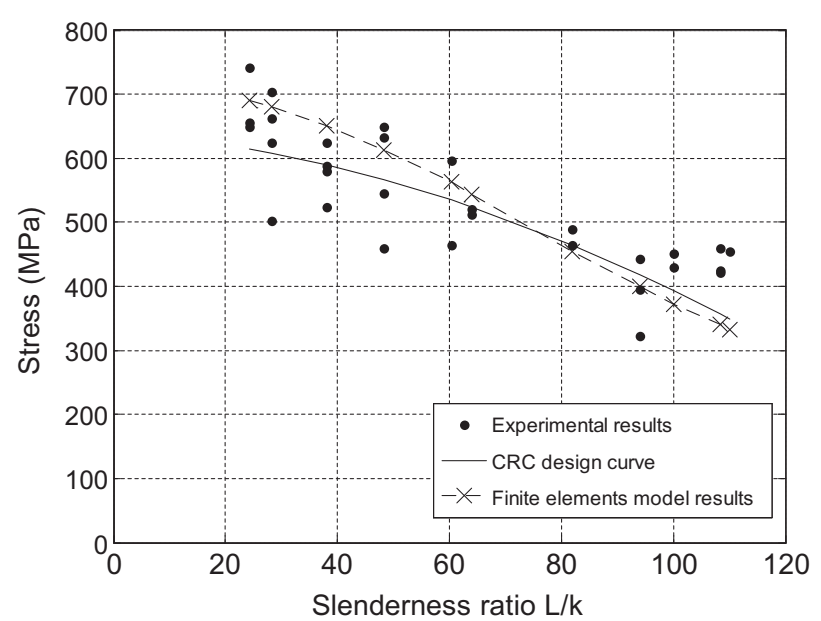

Fig. 4. Stresses at instability point in relation to slenderness $\mathrm{L} / \mathrm{k}$ of the steel bars.

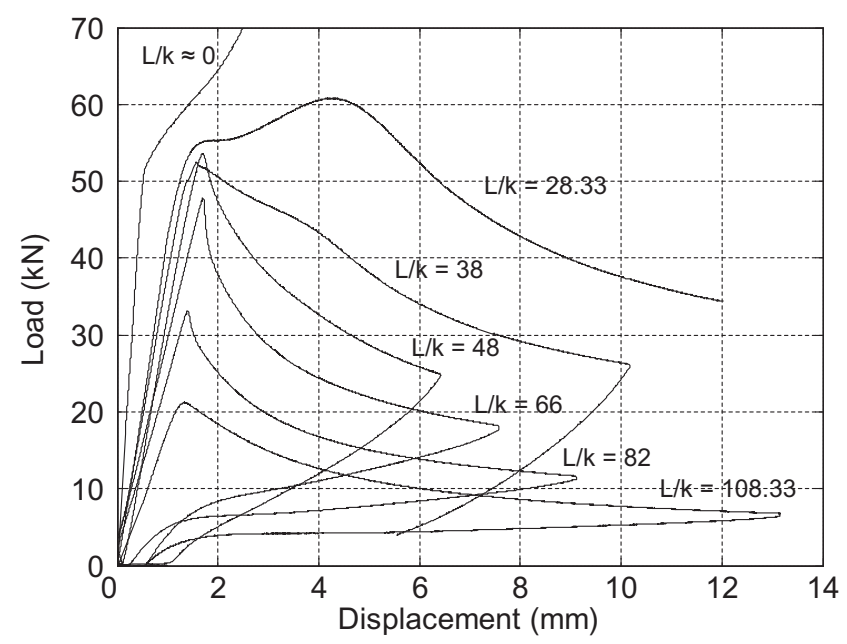

(a)

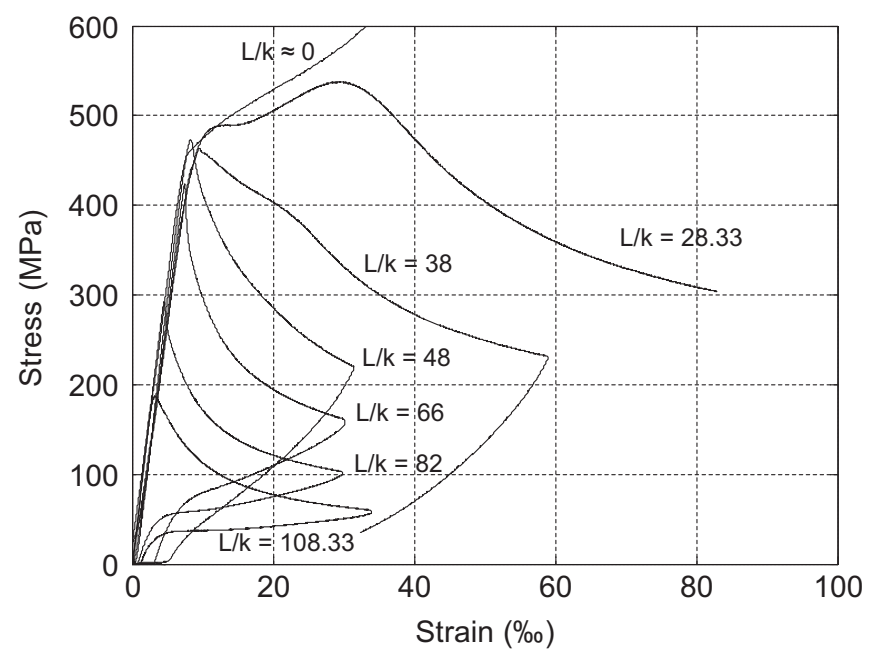

(b)

Fig. 5. Experimental results for several $\mathrm{L} / \mathrm{k}$ slendernesses for the SMA bars: (a) Load $(\mathrm{kN})$ - displacement (mm); (b) Stress (MPa) - Strain (\%o). adjustment of experimental results and the theoretical CRC curve is 0.98 .
Fig. 5 shows the results of the Ni-Ti bars for different $L / k$ slenderness levels. The load-displacement diagram is represented (as the mean value of the two LVDTs), which is obtained directly from the test. The average stress - equivalent strain diagram is also displayed. Equivalent strain was calculated by dividing measured displacement by the bar free length $L$. This figure shows the behavior of the Ni-Ti bar under compression with no second-order effects as a reference $(L / k \approx 0)$. This behavior was very sensitive to changes in slenderness $L / k$. For the shortest bar $(L / k=28.33)$, the load of the bar increased and experienced phase transformation at $470 \mathrm{MPa}$. At this point, bar instability in compression took place due to the decrease of the tangent elasticity modulus, as the material entered the martensitic transformation phase. Yet unlike what happened with steel, the supported load did not decrease with the increase of bar strain beyond this instability point. In this case, the applied load increased because, given the bending, the most compressed end fibers of the section gradually completed their transformation into martensite. Despite the slope of the curve is positive beyond this point, it has been called instability point because the slope may be positive or negative depending on the slenderness of the bar and the cause that governs the phenomenon is the same in all cases: the material entered the martensitic transformation phase.

Therefore, due to the asymmetry of the fundamental stressstrain relation of $\mathrm{Ni}-\mathrm{Ti}$ under compression, the martensitic transformation ended for a lower strain under compression than under tension (Fig. 2). As the martensitic elasticity modulus was greater than the transformation elasticity modulus, the material stiffness and the bending moment increased. From a strain of 30\%o, the load began to decrease because of the increasing bending moment due to second-order effects. Therefore, two instability points were observed in this specimen, which is a particular characteristic of $\mathrm{Ni}$-Ti bars [37]. As expected, pure compression behavior dominated the stress-strain relation for low slenderness values.

Regarding the stress-strain curve $L / k=38$, the stress at which instability occurred was similar to the previous case for $L / k=28.33$ because of the same cause (start of phase transformation). Nonetheless, the load after the instability point, in this case, did not increase after instability, unlike in the previous case, but a change was noticed in behavior with a strain of approximately $21 \%$. This point was similar to the second instability point in $L / k=28.33$ but, as slenderness was higher, this point was unable to exceed the previously accomplished maximum load. As can be seen, the behavior under pure compression moved away as $L / k$ rose.

In $L / k=48$, the stress at which instability occurred was roughly equal to former cases. This instability occurred once again because SMA entered phase transformation and the elasticity modulus drastically decreased. Unlike in previous cases, the post-peak branch fell uniformly. There was no second instability point, unlike in $L / k=28.33$, and there were not different behaviors observed in this branch, unlike in $L / k=38$.

In all the other cases $(66 \leq L / k \leq 108.33)$, stress at instability point was below that which corresponded to the start of phase transformation. In these cases, instability occurred in the austenite phase. As expected, stress at instability point and the corresponding strain were lower as the slenderness ratio increased. The postpeak branch uniformly fell in all cases.

Table 2 compares the critical stresses experimentally obtained $\sigma_{\text {crit_exp }}$ with the critical load according to Euler. As it has been aforementioned, $\alpha$ value of 0.57 was employed instead of 0.5 , which corresponds to the fully fixed bar, because the bar was not perfectly fixed in the tests. This was proved by the deformations in the plate cases at the end of the tests. Consequently, free length of bars could be multiplied by $0.57 / 0.5$ to obtain the equivalent free 
Table 2

Comparison between Euler critical and experimental critical stress. Experimental residual strains.

\begin{tabular}{llll}
\hline$L / k$ & $\sigma_{\text {crit_Euler }}(\mathrm{MPa})$ & $\sigma_{\text {crit_exp }}(\mathrm{MPa})$ & $\varepsilon_{\text {res_exp }}(\%)$ \\
\hline 28.33 & 2421.78 & 483.48 & - \\
38.00 & 1346.37 & 464.29 & 3.50 \\
48.00 & 843.82 & 473.66 & 1.03 \\
66.00 & 446.32 & 423.35 & 0.59 \\
82.00 & 289.14 & 293.11 & 0.25 \\
108.33 & 165.66 & 187.45 & 0.54 \\
\hline
\end{tabular}

length considering bars fully fixed. The experimental results for the range of slendernesses between 66 and 108.33 were similar to the Euler ones (elastic buckling). No correlation was found for the other slendernesses because bar instability took place when transformation phase began.

One significant aspect of Ni-Ti bars is that they can recover most of the strain they undergo during the cycle thanks to their superelasticity capacity. Thus, bars presented small residual strain values once the cycle finished because, as it is stated in Section 2.1, the bars were not completely superelastic. This is due to the fact that the martensite induced by stresses after the instability point was converted again into austenite after unloading. The measured residual strain values after completing the cycle $\varepsilon_{\text {res_exp }}(\%)$ are provided in Table 2, which shows the degree of recovery. As Table 2 indicates, this recovery was greater for higher slenderness $L / k$ ratios. With specimen $L / k=28.33$, unloading was impossible due to a problem with the hydraulic actuator. The valve to reverse the direction of the oil failed. Regarding the steel bars, they presented some large plastic strains.

\section{Numerical simulation}

Numerical simulation was carried out using the commercial Abaqus [50] finite element software. The aim of this simulation was to perform numerical tests to increase the number of available tests in order to propose an analytical constitutive model of isolated Ni-Ti bars including instability in compression (Section 4). The 30 experiments carried out with steel bars and the 6 experiments conducted with $\mathrm{Ni}$-Ti bars were numerically reproduced.

\subsection{Description of the finite elements, boundary conditions and applied loads}

The finite elements employed were hexahedral with eight nodes and three degrees of freedom per node, and with reduced integration and hourglass control (C3D8R) [50]. The edge of each hexahedron measured $1.5 \mathrm{~mm}$ on average. This value was chosen because it provided an adequate ratio between precision of results and time needed for calculation (Fig. 6). In order to show the mesh and the finite element results, a contour plot of the normal stresses resulting from the parametric study is displayed in Fig. 7. In this figure, the bar has a free length of $75 \mathrm{~mm}$.

The boundary conditions under which the model was run are illustrated in Fig. 8. The total length of the bar was simulated. All the degrees of freedom of one end were coactioned, and all those of the other end were also coactioned, except for the displacement on the bar direction line. In order to model the interaction between the bar and the cases of the steel plates of the experimental test (not fully fixed condition), two springs were included, each one at the point where the bar was supported on the cases when it became unstable due to compression. The springs constrain the displacement degrees of freedom (not rotational ones) perpendicular to the undeformed bar springs. The bar length supported on the cases was $1.5 \mathrm{~mm}$ and it had a half-circumference width, based on the state of the cases when tests finished. The stiffness of these springs was calibrated comparing the steel bar tests with the experimental tests. The calibrated stiffness per area unit was $13 \cdot 10^{5} \mathrm{MN} / \mathrm{m}^{3}$.

To achieve the initial irregularity that causes instability due to compression, an initial $10 \mathrm{~N}$ discrete load was applied to the center of the bar and perpendicularly to its direction line. This load was small enough to avoid the modification of the stress at instability point. Then, vertical displacement $v$ was applied (Fig. 8). Displacement control was performed in order to obtain the post-peak branch of the tests. The Newton based solution method was employed.

The convergence tolerances were mainly governed by the following parameters:

$-R_{n}^{\alpha}$ : Ratio of the largest residual to the corresponding average flux norm. The used value, which coincides with the default value is $R_{n}^{\alpha}=5 \times 10^{-3}$, which is strict by engineering standards. $-C_{n}^{\alpha}$ : Ratio of the largest solution correction to the largest corresponding incremental solution value. The used value (default value) is $C_{n}^{\alpha}=10^{-2}$. In addition to sufficiently small residuals (parameter $R_{n}^{\alpha}$ ), Abaqus [50] requires that the largest correction to the solution value be small in comparison to the largest corresponding incremental solution value.

Regarding number of steps and increments, the model initiates with a vertical imposed displacement of 0.001 times the value of the total imposed displacement. The following increments are calculated automatically, being the minimum fixed increment $10^{-7}$ and the maximum 0.005 . The maximum number of increments to get the total imposed displacement is 100,000 increments.

Geometric nonlinearity was taken into account. In this case elements are formulated in the current configuration using current nodal positions. Elements therefore distort from their original shapes as the deformation increases.

\subsection{Material constitutive models}

For the steel specimens, the elasto-plastic model in Abaqus [50] was applied with the following parameter values: $\mathrm{E}_{s}=150400 \mathrm{MPa}, v=0.3, \sigma_{y}=650 \mathrm{MPa}$, and three plastic branch points, $\quad \varepsilon_{1}=0.0052, \sigma_{1}=700 \mathrm{MPa}, \varepsilon_{2}=0.0082, \sigma_{2}=800 \mathrm{MPa}, \varepsilon_{3}=$ $0.1957, \sigma_{3}=900 \mathrm{MPa}$. These plastic points were used because of the broad transition between the elastic branch and the plastic branch. This transition was large enough not to be considered as simple bilinear behavior.

The fundamental stress-strain equation for the $\mathrm{Ni}-\mathrm{Ti}$ as material implemented in Abaqus [50], which was proposed by Auricchio et al. [48,51,52], was applied (Fig. 9). This equation considers the different behavior of SMA under tension and under compression. The parameters employed according to the nomenclature in Fig. 9 are as follows: $E_{a}=64647 \mathrm{MPa}, v_{a}=0.33, E_{M}=$ $28125 \mathrm{MPa}, v_{M}=0.33, \varepsilon_{L}=0.09,\left(\frac{\delta \sigma}{\delta T}\right)_{L}=6.7 \frac{\mathrm{MPa}}{{ }^{\circ} \mathrm{C}}, \sigma_{t L}^{S}=450 \mathrm{MPa}, \sigma_{t L}^{E}=$ $700, T_{0}=18.2^{\circ} \mathrm{C},\left(\frac{\delta \sigma}{\delta T}\right)_{U}=6.7 \frac{\mathrm{MPa}}{{ }^{\circ} \mathrm{C}}, \sigma_{t U}^{S}=200 \mathrm{MPa}, \sigma_{t L}^{E}=30 \mathrm{MPa}, \sigma_{c L}^{S}=$ $450 \mathrm{MPa}, \varepsilon_{V}^{L}=0.102$. In Fig. 10 the experimental constitutive curves are compared with the numerical model ones (Abaqus), and it is shown that there is sufficient degree of precision. It must be noted that the mechanical parameters were consistent with the characterization results. Since the temperature of the tests was the same as that of the characterization tests, the curve obtained in the characterization tests was used in the numerical simulation. Therefore, the Ni-Ti thermal parameters were not relevant.

Two points of plastic branch were included in accordance with the results of the stress-strain characterization carried out with the bars: $\varepsilon_{1}=0.125, \sigma_{1}=1100 \mathrm{MPa}, \varepsilon_{2}=0.25, \sigma_{2}=2707 \mathrm{MPa}$.
431 


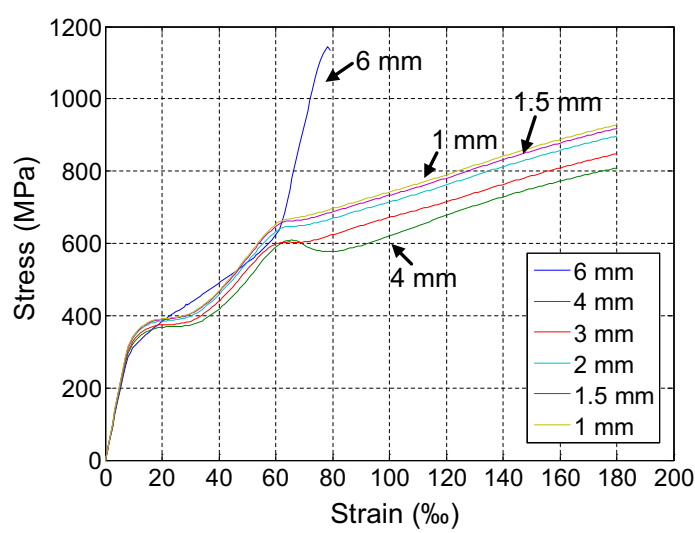

(a)

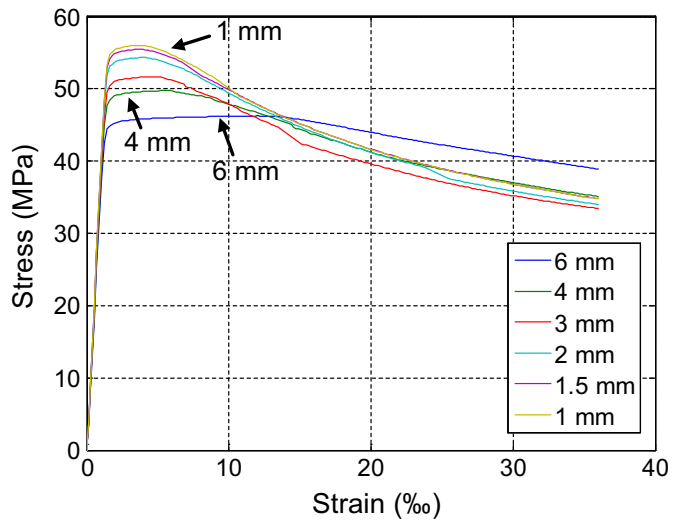

(b)

Fig. 6. Influence of finite element size on stress-strain response of compressed Ni-Ti bars: (a) bar length of $100 \mathrm{~mm}$; (b) bar length of $500 \mathrm{~mm}$.

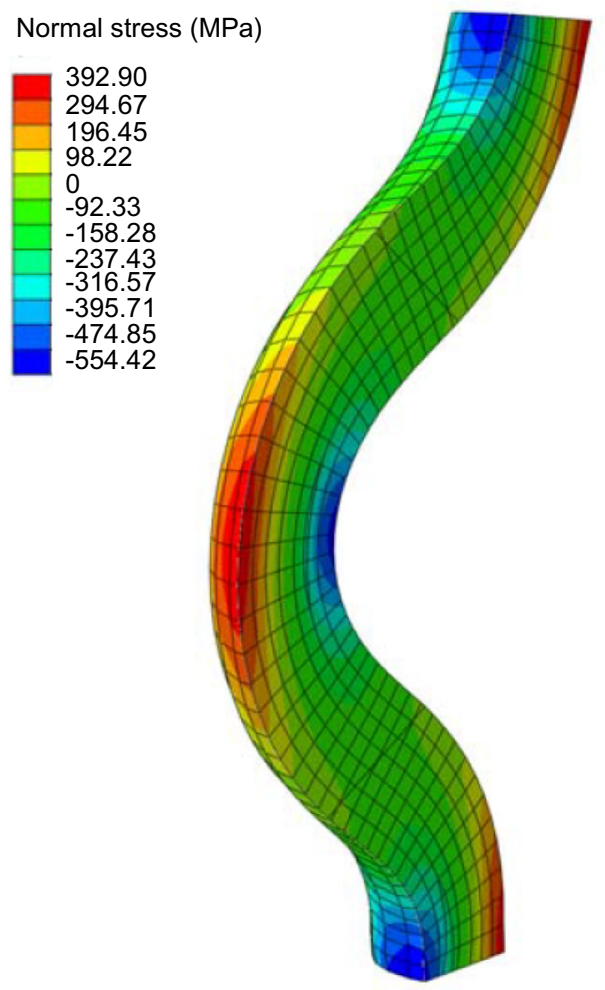

Fig. 7. Contour plot of normal stresses in a bar of $75 \mathrm{~mm}$.

These points of plastic branch were irrelevant under tension (the finite element model never reached even the martensitic branch under tension). However, they needed to be included so that the behavior under compression is correct because Abaqus [38] deduces the behavior under compression according to tension behavior through the volumetric strain parameter $\varepsilon_{V}^{L}$.

The fact that the behavior under compression was deduced from tension implies that it is a limitation in the numerical model. For this reason, the transformation branch length in tension $\varepsilon_{L}$ and the martensitic elasticity modulus in tension $E_{M}$ were also amended with respect to the real values, so that when the Ni-Ti behavior under tension was transformed into compression through the volumetric strain parameter $\varepsilon_{V}^{L}$, the real behavior of the bar could be obtained. This modification barely changes the model results.

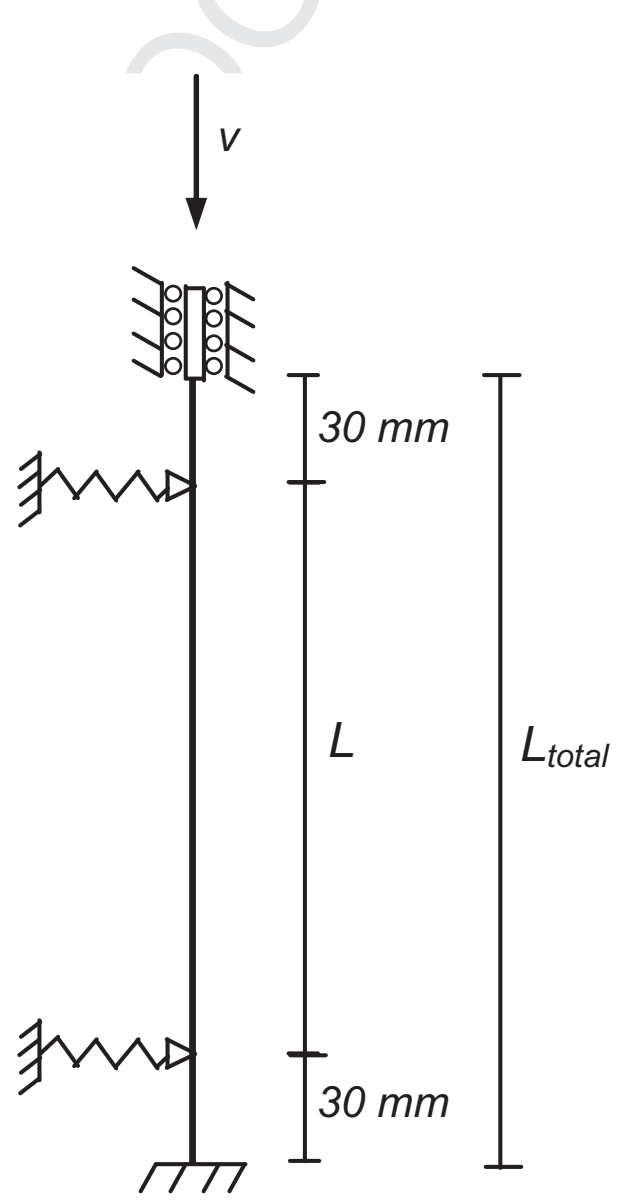

Fig. 8. The boundary conditions applied to the bar.

\subsection{Calibration and verification of the numerical model}

The results of the tests carried out with steel bars are summarized in Fig. 4, where the load at instability point is represented as a function of the slenderness of the bars $(L / k)$. The result allows the finite element model to be considered as valid, particularly the type of element chosen, the boundary conditions and the applied loads.

Fig. 11 shows the load-displacement curves corresponding to the $\mathrm{Ni}$-Ti bars, which were obtained by the experimental tests and by the numerical model. A good correlation of the results was obtained in both loads and displacements. Therefore, the 


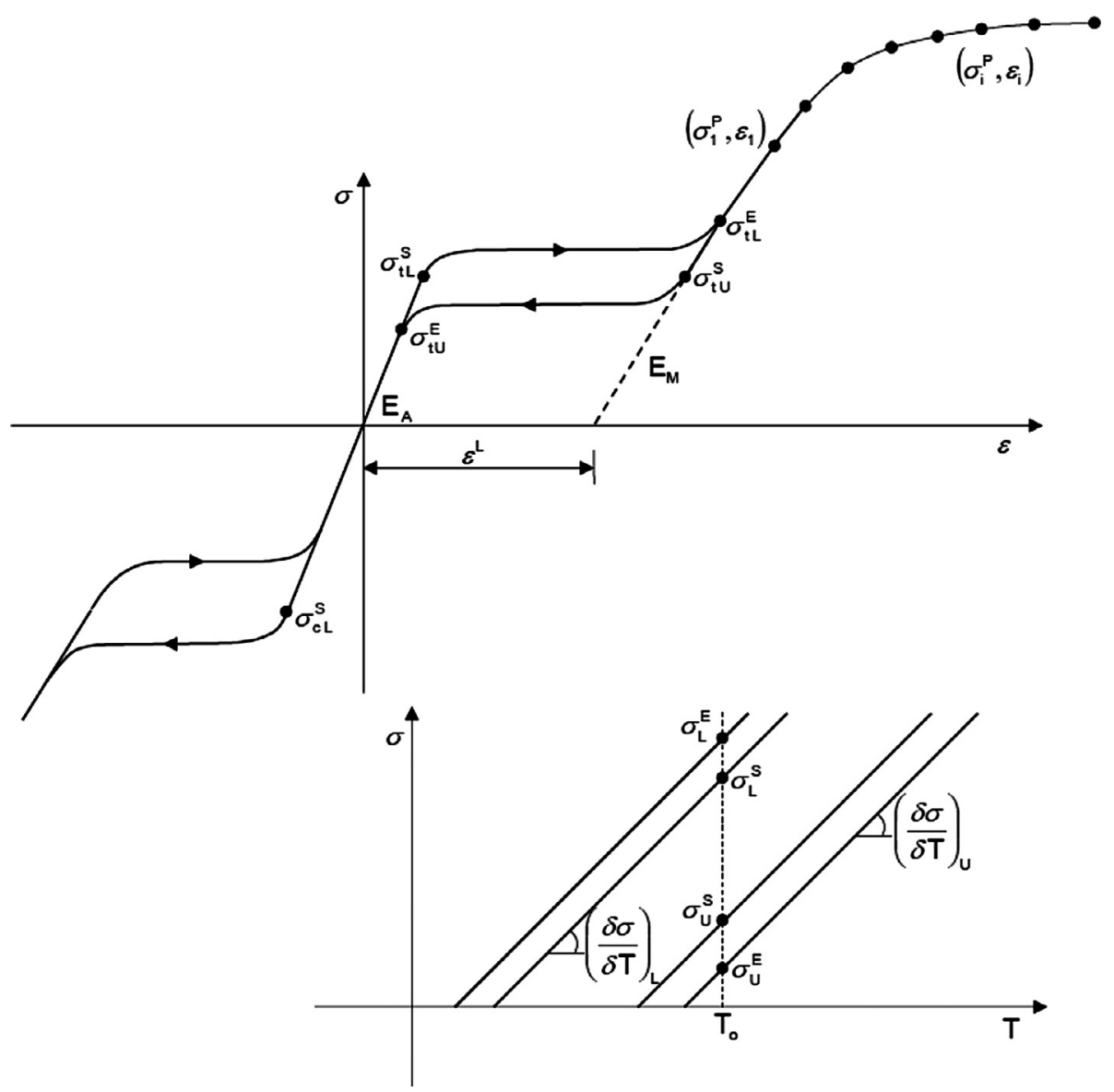

Fig. 9. The Abaqus SMA material model [38] proposed by Auricchio et al. [48,51,52].

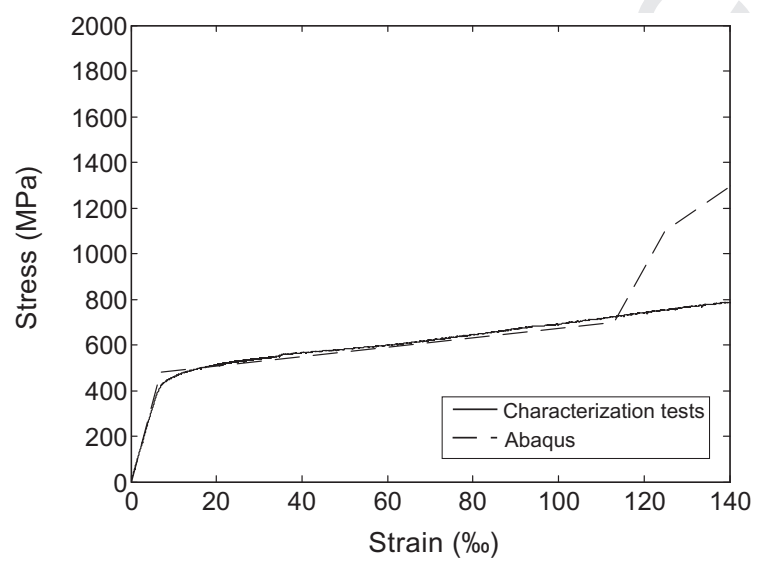

(a)

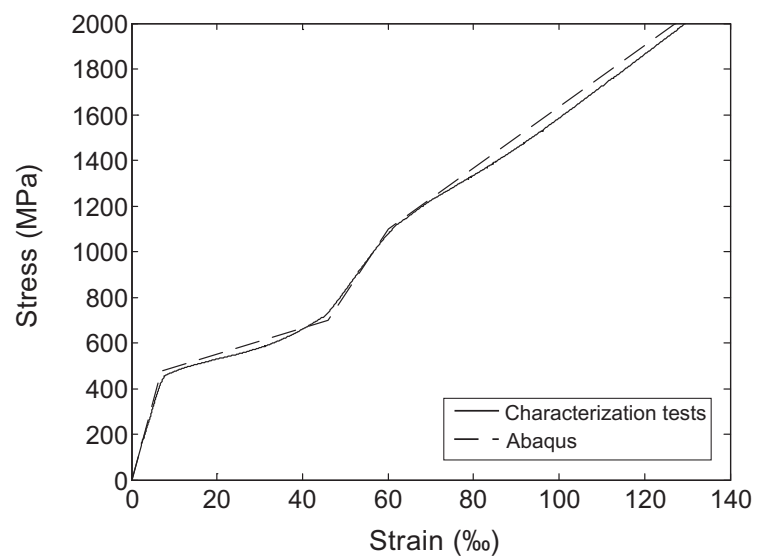

(b)

Fig. 10. Fundamental stress-strain diagram of Ni-Ti: (a) under tension; (b) under compression.

numerical model has been calibrated based on experimental results. In the case of low slendernesses, $L / k=28.33$ and $L / k=38$, the numerical model was capable of detecting not only the two instability points if $L / k=28.33$, but also the change in the slope of the descending branch if $L / k=38$. Both phenomena took place due to increasing bar stiffness when more compressed fibers of the section completed martensitic transformation. The finite element model also showed that the slenderest bars $(L / k=66$,
$L / k=82$ and $L / k=108.33$ ) underwent elastic buckling as the whole section was in the austenite phase.

\subsection{Parametric study: results and discussion}

A parametric study was carried out with the Abaqus commercial software [50]. The objectives of the present study are to extend the existing compressed bar tests through numerical tests to ana- 


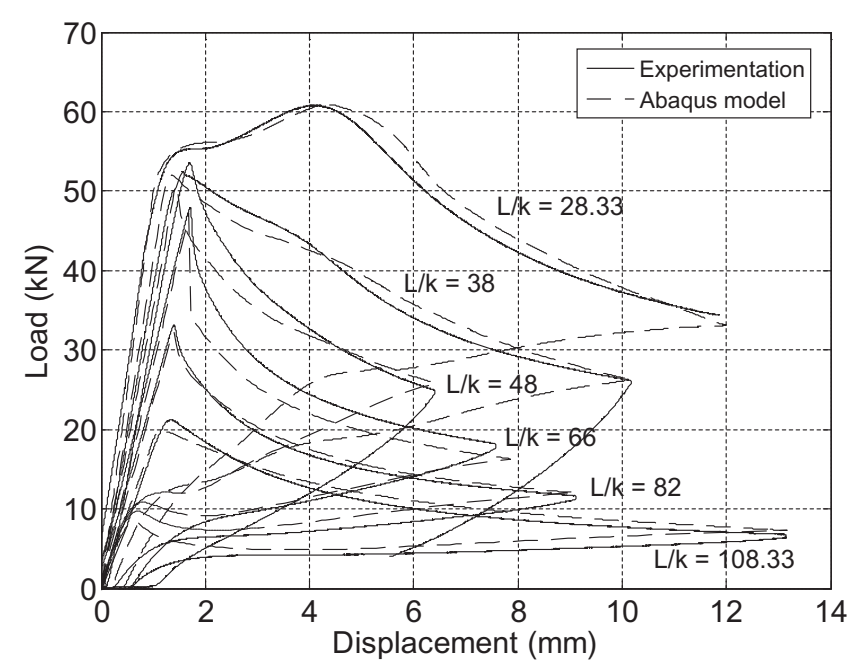

Fig. 11. Load-displacement curves of the experimental data and the finite element model made by Abaqus [50].

Table 3

Values of the parameters used in the parametric study.

\begin{tabular}{lll}
\hline Parameters & & Values \\
\hline Bar length & $L(\mathrm{~mm})$ & $100,200,500,1000$ \\
Austenitic elasticity modulus & $E_{A}(\mathrm{MPa})$ & 40000,65000 \\
Martensitic elasticity modulus & $E_{M}(\mathrm{MPa})$ & 40000,20000 \\
$\begin{array}{l}\text { Stress at the start of transformation } \\
\quad \text { in tension }\end{array}$ & $\sigma_{t L}^{S}(\mathrm{MPa})$ & 300,500 \\
$\quad \begin{array}{l}\text { Stress at the start of transformation } \\
\quad \text { in compression }\end{array}$ & $\sigma_{c L}^{S}(\mathrm{MPa})$ & 300,500 \\
$\quad$ Volumetric strain & $\varepsilon_{V}^{L}$ & $0,0.055$ \\
\hline
\end{tabular}

lyze the influence of other factors that cannot be studied in the experimental campaign, such as the influence of the Ni-Ti austenitic and martensitic tangent moduli, $E_{A}$ and $E_{M}$ respectively (Fig. 9), and the influence of the asymmetric tension-compression behavior.

The same configuration of the Abaqus [50] model which was employed in Sections 3.1 and 3.2 was used, except that the boundary condition of the horizontal springs was removed. In the parametric study, it was considered that $L=L_{\text {total }}$, and that perfect fixed ends occurred.

The parameters that were modified to undertake the parametric study are presented in Table 3, and refer to bar slenderness and the constitutive Ni-Ti characteristics. The nomenclature is the same as that employed in the constitutive SMA equation put forward in Abaqus [48,51,52] (Fig. 9). The list of bar lengths 100, 200, 500 and $1000 \mathrm{~mm}$ corresponds to the following slendernesses $L / k$ : $33.3,66.6,166.6$ and 333.3, respectively. It was analyzed how a different austenitic and martensitic elasticity modulus, $E_{A}$ and $E_{M}$ respectively, can influence behavior. The influence of asymmetric behavior is studied from two points of view: under stresses and under strains. Under stresses, there is an asymmetry when stress at the start of transformation in tension $\sigma_{t L}^{s}$ is different than that in compression $\sigma_{c L}^{S}$. The amendment of these stresses means that the whole curve is modified under stresses; e.g., the stresses at the end of transformation $\left(\sigma_{t L}^{E}\right.$ and $\left.\sigma_{c L}^{E}\right)$. Under strains, when defining a different transformation branch length in tension from that in compression with the volumetric strain parameter $\varepsilon_{V}^{L}$. If $\varepsilon_{V}^{L}$ equals zero, then the transformation branch length is equal in both tension and compression. Strain $\varepsilon_{L}$, which was introduced in Abaqus [50], varies according to the expression $\varepsilon_{L}=0.05-\frac{\sigma_{t u}^{E}}{E_{M}}+\frac{\sigma_{t}^{S}}{E_{A}}$ so that the transformation branch length under tension is always 0.05 .
The thermal-mechanical characteristics remain constant, as well as the $12-\mathrm{mm}$ diameter. Ninety-six numerical tests were carried out.

After analyzing the parametric results, a comparison made between pairs of specimens is shown in Fig. 12, where only the austenitic elasticity modulus varies (Fig. 12a and b), or the martensitic elasticity modulus (Fig. 12c and d), or asymmetry appears in the tension-compression behavior by varying only the compressed transformation branch length (Fig. 12e), or by varying the stresses of the start and end of the martensitic transformation phase (Fig. 12f). The Abaqus [50] parameters employed in the tests shown in Fig. 12 follow this nomenclature: $L_{-} \sigma_{t L}^{S} \sigma_{c L}^{S} E_{A} E_{M}$ _ $\varepsilon_{V}^{L}$, for instance: 500_300_500_40000_20000_0.

Austenitic elasticity modulus $E_{A}$ has an influence for high $L / k$ ratios (Fig. 12a) in situations of instability within the elastic range. Obviously, the lower the austenitic elasticity modulus $E_{A}$, the lesser the stress at which instability takes place (Euler). However, for low $L / k$ ratios, this parameter is not important, because $\mathrm{Ni}-\mathrm{Ti}$ behavior is governed by the transformation phase elasticity modulus or by the martensitic elasticity modulus $E_{M}$ (Fig. 12b). As a result, it is shown that two instability points are generated, and that a stable configuration after the instability point occurs between the first and second instability points.

Fig. 12c shows the influence of the martensitic elasticity modulus and how this parameter is important for low slenderness levels. When slenderness levels are low, more fibers from the section complete the transformation into martensite, and the elasticity modulus of the martensite branch becomes more important. Fig. 12c shows that the load does not decrease because the Ni-Ti plastic branch is not included, so the martensitic branch indefinitely grows. On the other hand, for high $\frac{L}{k}$ ratios (Fig. 12d), the influence of this parameter is not that important, unlike what happens with the austenitic elasticity modulus parameter.

Regarding the tension-compression asymmetry on the transformation branch length, Fig. 12e shows two curves where the constitutive behavior under compression varies in relation to that under tension on the transformation branch length in terms of strain. The transformation branch length is 0.05 for tension and 0.021 for compression (for an Abaqus volumetric strain [38] of $\varepsilon_{V}^{L}=0.055$, if asymmetry exists). The branch after the instability point has a slope with a lower absolute value if the aforementioned asymmetry is considered, since the transformation branch elasticity modulus is higher.

Finally, in Fig. 12f, specimens possess a tension-compression asymmetry in the stresses at the start and end of the martensitic phase transformation. Under tension, these are 300 and $600 \mathrm{MPa}$ respectively, whereas the values are 500 and $1000 \mathrm{MPa}$ respectively for compression (the software automatically gives the stress of $1000 \mathrm{MPa}$, which cannot be modified). For low slenderness levels, as shown in Fig. 12f, the importance of asymmetry on the stress values is considerable because the first instability point is produced when the transformation branch begins. One aspect to be highlighted in Fig. $12 \mathrm{f}$ is that despite a specimen enters the transformation phase before another specimen, their stresses after the instability point are equal afterwards. This happens because the specimen that enters the transformation phase first is able to increase the supported load to a greater extent than the other specimen, since the former specimen completes martensitic transformation sooner.

\section{Analytical model to calculate the behavior of the bars including the instability in compression}

This section proposes an analytical model to determine the monotonic constitutive average stress - equivalent strain relation- 


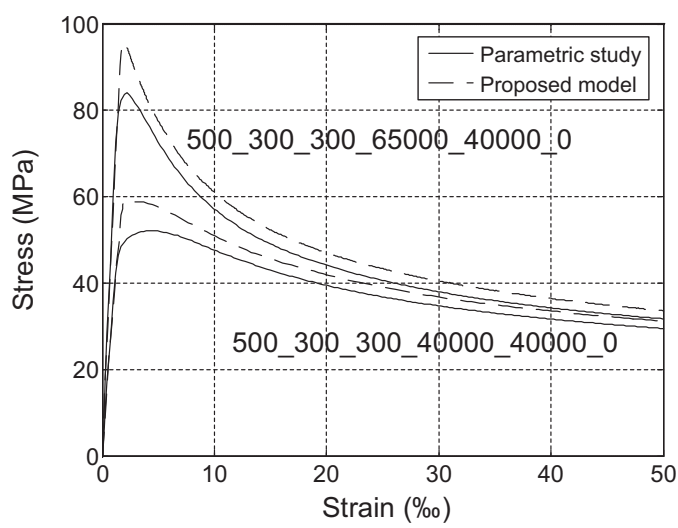

(a)

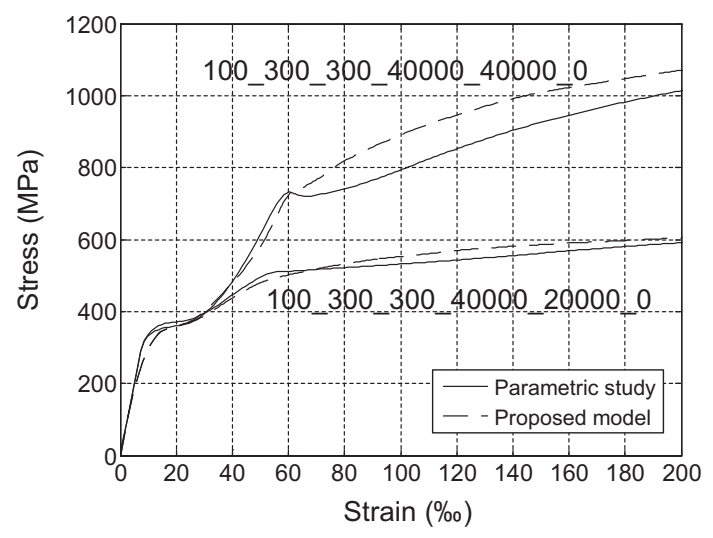

(c)

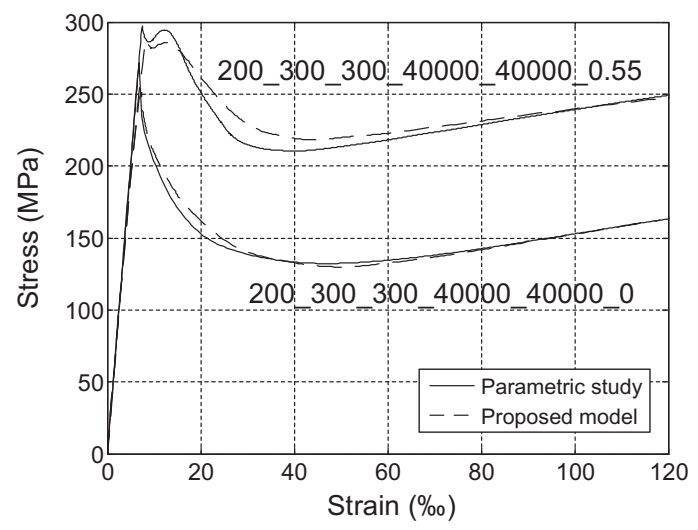

(e)

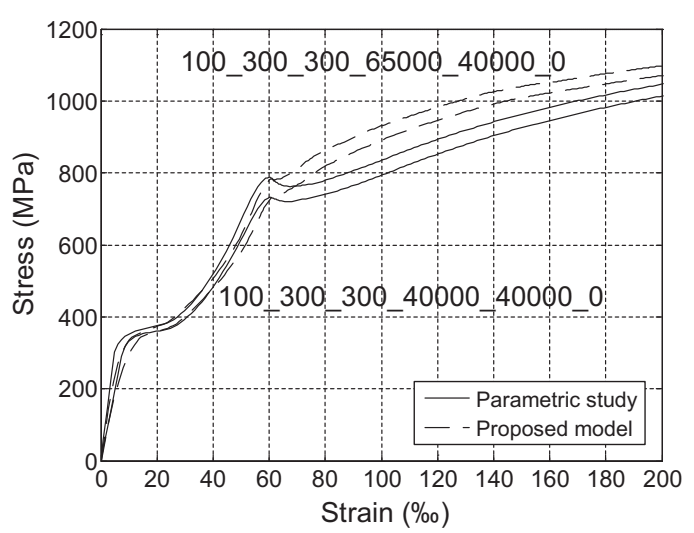

(b)

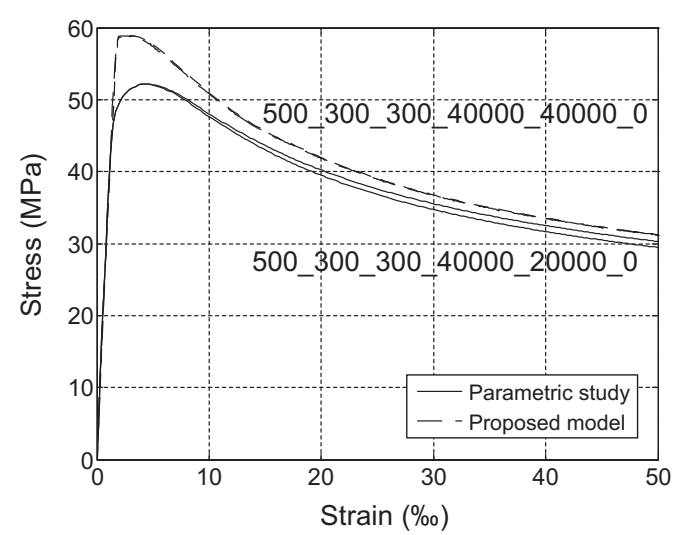

(d)

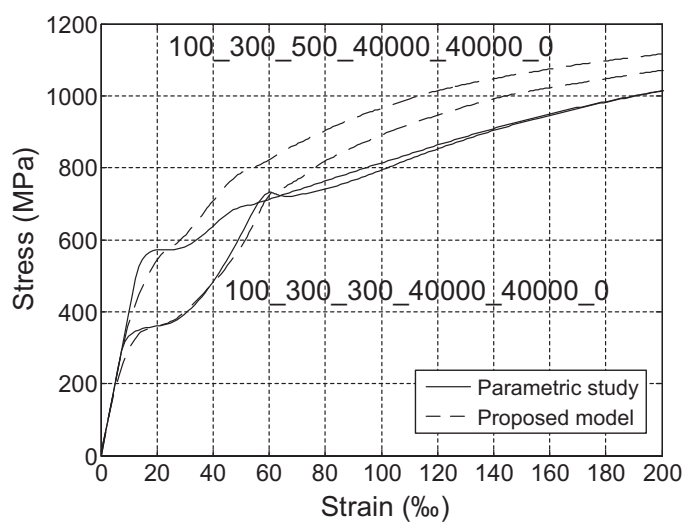

(f)

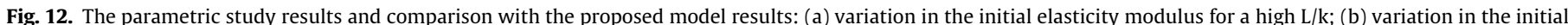

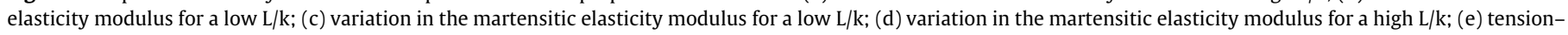

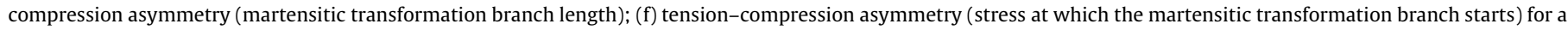
low $\mathrm{L} / \mathrm{k}$.

ship $\left(\sigma_{s r}-\varepsilon_{s r}\right)$ under compression for Ni-Ti bars, including second order instability. The model was validated with the experimental results described in Section 2 and with the results of the parametric study conducted in Section 3. The models that are found in the research literature for the steel constitutive curves which include the behavior after the instability point $[17,18,40]$ cannot be used for $\mathrm{Ni}-\mathrm{Ti}$, since the Ni-Ti constitutive curve is not symmetrical in tension-compression and Ni-Ti does not have a bilinear behavior with a horizontal plastic branch.

\subsection{Proposal of the model}

The procedure assumes a cosine shape of the deformed geometry for the bar subjected to second order instability in compression [53] according to Eq. (1) [54] (Fig. 13).

$$
y(x)=\left(y_{0} / 2\right)[1-\cos (2 \pi x / L)]
$$

where

$x$ : Position in the direction of the undeformed bar direction line 


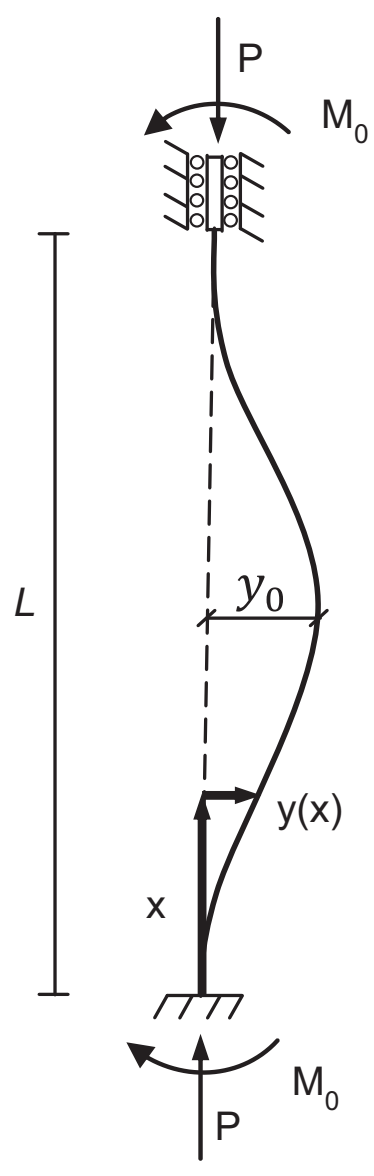

Fig. 13. Free-body diagram of bar. $y(x)$ : Lateral bar displacement at position $x$

$L$ : Fully fixed bar length

$y_{0}$ : Displacement in direction $y$ at position $x=\frac{L}{2}$

To find out the Ni-Ti constitutive curve including the second order instability effect, the variation of work of internal forces is made equal to the external ones, in line with the virtual work principle. Symbol $\delta$ expresses variation in the associated variable.

$\delta W_{\text {ext }}=-\delta W_{\text {int }}$

If the hypothesis that the system is elastic is adopted, the work that external forces exert on the system is stored as strain energy in the system:

$\delta W_{\text {ext }}=\delta U=-\delta W_{\text {int }}$

The internal energy expression for a solid that displays tridimensional elastic behavior (linear or nonlinear), according to Chen and Lui [46], is:

$U=\int_{V} \int_{\varepsilon_{1}}^{\varepsilon_{2}} \sigma_{i j} \cdot d \varepsilon_{i j} \cdot d V$

Where

$\sigma_{i j}:$ Stress tensor

$\varepsilon_{i j}$ : Strain tensor

$V$ : Element volume

$\varepsilon_{1}$ : The initial strain tensor value

$\varepsilon_{2}$ : The final strain tensor value

If Eq. (4) is expressed in a variational manner, it adopts the form of Eq. (5). $\delta U=\int_{V} \sigma_{i j} \cdot \delta \varepsilon_{i j} \cdot d V$

If the hypothesis is assumed that plane sections before being deformed remain plane after deforming (hypothesis of NavierBernoulli), then the equation below applies for a unidimensional material with both linear and nonlinear behaviors (Fig. 14):

$\delta \varepsilon(x, z)=\delta \varepsilon_{0}(x)+z \cdot \delta c(x)$

Where

$x$ : Coordinate of the section in the bar direction line (Fig. 13). $z$ : Coordinate of the fiber of the bar section perpendicular to its direction line, whose origin lies in the section center of gravity (Fig. 14).

$\varepsilon(x, z)$ : Strain of the fiber located on the coordinates $(x, z)$.

$\varepsilon_{0}(x)$ : Strain in the reference center of the forces in the section.

The reference center of sectional forces is taken as the section center of gravity.

$c(x)$ : Curvature of the section placed at position $x$.

As the shape equation of the bar subject to instability in compression is known (1), the curvature of section $c(x)$ is obtained using the following equation:

$c(x)=\frac{\partial^{2} y(x)}{\partial x^{2}}=\frac{2 \pi^{2}}{L^{2}} \cdot y_{0} \cdot \cos (2 \pi x / L)$

If Eq. (5) is specified for a unidimensional solid and Eq. (6) is substituted in Eq. (5), the following equality is obtained:

$$
\begin{aligned}
\delta U= & \int_{x=0}^{x=L} \int_{z=-R}^{z=R} \sigma \cdot \delta \varepsilon_{0}(x) \cdot b(z) \cdot d z \cdot d x+\int_{x=0}^{x=L} \int_{z=-R}^{z=R} \sigma \cdot z \cdot \delta c(x) \\
& \cdot b(z) \cdot d z \cdot d x
\end{aligned}
$$

where: $b(z)$ : Section width on coordinate $z$ (Fig. 14).

If the terms in Eq. (8) are grouped, we obtain:

$\delta U=\int_{x=0}^{x=L} N(x) \cdot \delta \varepsilon_{0}(x) \cdot d x+\int_{x=0}^{x=L} M(x) \cdot \delta c(x) \cdot d x$

where: $N(x)$ : Axial force in a section located at position $x$ of the direction line:

$N(x)=\int_{-R}^{R} \sigma(\varepsilon(x, z)) \cdot b(z) \cdot d z$

where

$\sigma(\varepsilon(x, z))$ : Ni-Ti stress in the fiber found at position $(x, z)$, for strain $\varepsilon(x, z)$. This stress is obtained from the fundamental constitutive stress-strain relation of $\mathrm{Ni}-\mathrm{Ti}$ as material (without including structural aspects such as second order effects). Therefore, it is necessary to know previously the fundamental constitutive equation in tension and compression of $\mathrm{Ni}-\mathrm{Ti}$ as material in order to apply the analytical model. These fundamental relations are considered at the temperature at which the average stress - equivalent strain relationship wants to be known.

$R$ : Bar radius

$M(x)$ : The bending moment on a section located at position $x$ of the direction line:

$M(x)=\int_{-R}^{R} \sigma(\varepsilon(x, z)) \cdot b(z) \cdot z \cdot d z$

The axial force $N(x)$ of each section found at position $x$ is related with the compression load $P$ applied to the ends of bars (Fig. 13) using the following equation:

$N(x)=P \cdot \cos \left(y^{\prime}(x)\right)$

where: $y^{\prime}(x)=\left(y_{0} \pi / L\right) \cdot \operatorname{sen}(2 \pi x / L)$. 


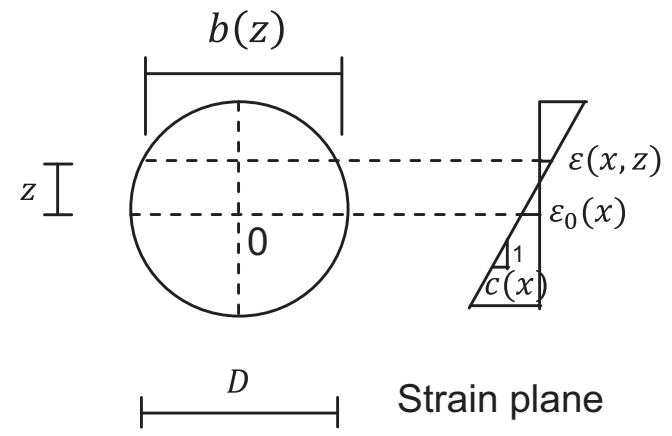

Fig. 14. Section and strain plane of the bar for coordinate $x$.

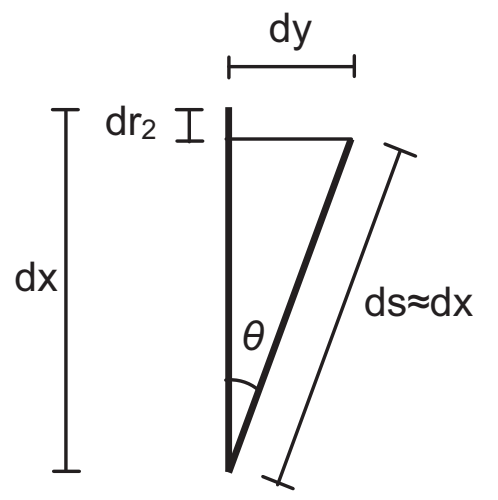

Fig. 15. Differential bar shortening due to bending $\left(\mathrm{r}_{\mathrm{b}}\right)$.

Variation in the work done by external forces takes the following equation [46]:

$\delta W_{\text {ext }}=P \cdot \delta r$

where $r$ : Bar shortening in direction $x$ as a result of applying load $P$.

This shortening is the sum of the shortening due to axial force $r_{a}$ and the shortening due to bending moment $r_{b}$ (Fig. 15) $\left(r=r_{a}+r_{b}\right)$ :

$r_{a}=\int_{x=0}^{x=L} \varepsilon_{0}(x) \cdot d x$

$r_{b}=\int_{0}^{L}\left[\sqrt{1+\left(\frac{d y}{d x}\right)^{2}}-1\right] d x \approx \frac{1}{2} \int_{0}^{L}\left(\frac{d y}{d x}\right)^{2} d x=\frac{\left(y_{0} \pi\right)^{2}}{4 L}$

If Eqs. (9) and (13) are substituted in (3) and solved for force $P$, the following equation is obtained:

$P=\frac{\delta U}{\delta r}=\frac{\int_{x=0}^{x=L} N(x) \cdot \delta \varepsilon_{0}(x) \cdot d x+\int_{x=0}^{x=L} M(x) \cdot \delta c(x) \cdot d x}{\delta r}$

The mean axial compressive stress $\sigma_{s r}$ on the Ni-Ti bar is considered to be equal to $P / A$, where $A$ is the bar section area, and the compression strain $\varepsilon_{s r}$ on the SMA bar equals $r / L$, where $r$ is total bar shortening and $L$ is bar length. Eq. (16) provides the monotonic constitutive stress-strain relationship $\left(\sigma_{s r}-\varepsilon_{s r}\right)$ under compression for $\mathrm{Ni}$-Ti bars, including the second order effect due to instability.

The employed constitutive model considers the material as elastic and non-linear, whereas the finite element model does consider a different branch for loading and unloading. The influence on the result of whether to consider the unloading or not has been compared, and no significant differences have been observed.

\subsection{Problem resolution}

Fig. 16 shows the flow chart to obtain the constitutive average stress - equivalent strain relationship $\left(\sigma_{s r}-\varepsilon_{s r}\right)$ of the Ni-Ti bars under compression for monotonic loads. For this purpose, the bar is previously divided into a sufficient number of elements.

The solution is carried out by displacement control. The $\sigma_{s r}-\varepsilon_{s r}$ relationship of the Ni-Ti bar is obtained by successively increasing shortenings by bending $r_{b}$. Each increase implies determining a new equilibrium position for one instant $t+\Delta t$. It is assumed that the equilibrium in the former instant $t$ is known. So, in instant $t=0$, stress $\sigma_{s r}$ and strain $\varepsilon_{s r}$ are null in the SMA bar. Consequently, the applied compression force $P$ is null.

To obtain a new equilibrium position in $t+\Delta t$ for shortening by bending $r_{b}$, the force $P$ value is taken as a reference of the former instant $t, P=P(t)$. The displacement in the central bar section $y_{0}$ is calculated by using Eq. (15):

$y_{0}=\sqrt{\frac{4 \cdot r_{b} \cdot L}{\pi^{2}}}$

Then the distribution of curvatures $c(x)$ is calculated in any bar section from Eq. (7). In each section located on the bar position $x$, strain is calculated in the reference center of sectional forces $\left(\varepsilon_{0}(x)\right)$ from the axial load equilibrium equation. Eqs. (10) and (12) are equaled for this purpose:

$N(x)=P \cdot \cos \left(y^{\prime}(x)\right)=\int_{-R}^{R} \sigma(\varepsilon(x, z)) \cdot b(z) \cdot d z$

In each section found at position $x$, bending moment $M(x)$ is obtained from Eq. (11), while shortening by axial force $r_{a}$ is obtained from Eq. (14). Bar shortening $r$ is obtained as the sum of the imposed shortening by bending $r_{b}$ and the calculated shortening by axial force $r_{a}$. Variation in the shortening of the bar $\delta r$ is obtained as the difference between the shortenings of the two successive intervals $t$ and $t+\Delta t$.

$\delta r=\left(r_{a}+r_{b}\right)^{t+\Delta t}-\left(r_{a}+r_{b}\right)^{t}$

Variation in internal energy $\delta U$ is obtained as the difference in internal energy between the two successive intervals $t$ and $t+\Delta t$.

$$
\begin{aligned}
\delta U= & (U)^{t+\Delta t}-(U)^{t}=\int_{x=0}^{x=L} \int_{t}^{t+\Delta t} N(x, t) \cdot \varepsilon_{0}(x, t) \cdot d t d x \\
& +\int_{x=0}^{x=L} \int_{t}^{t+\Delta t} M(x, t) \cdot c(x, t) \cdot d t d x
\end{aligned}
$$

The compression load $P(t+\Delta t)$ applied to the ends of the bar that corresponds to interval $t+\Delta t$ is obtained from Eq. (16). As this load does not coincide with load $P$, taken as a reference, force $P$ is modified by taking the calculated force $P(t+\Delta t)$ as reference until convergence is reached.

Finally, stress $\sigma_{s r}$ and strain $\varepsilon_{s r}$ are obtained for the shortening $r_{b}$ value. To obtain another $P(t+\Delta t)$ value, shortening $r_{b}$ must be increased and the force $P(t)$ value that corresponds to instant $t$ is taken as the reference force $P$.

\subsection{Validation of the proposed model}

The validation of the model proposed above is reported in this section. Validation is done by comparing the results of the numerical tests of the parametric study with those of the proposed model. A comparison is also made with the experimental results. The constitutive equation used in the analytical model is the one shown in Fig. 2 when the comparison is made with the experimental tests. When the comparison is made with the numerical tests from the parametric study, the constitutive equation used in the 


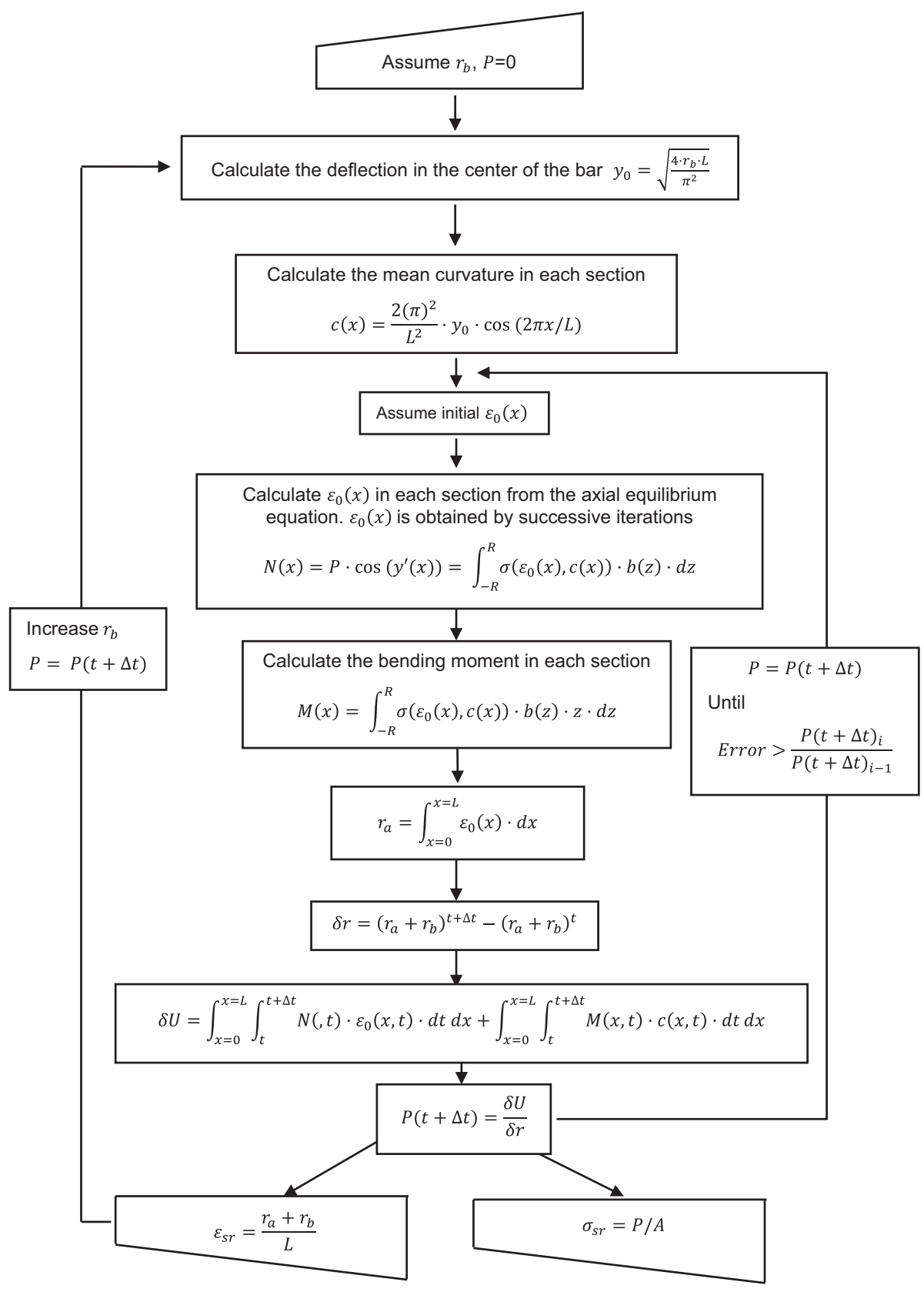

Fig. 16. Flow chart to solve the analytical model.

analytical model is the one employed in each numerical simulation.

In Fig. 12 the results of the proposed model and those in the numerical tests obtained from the parametric study are compared. No convergence problems were observed using the proposed analytical model, unlike what happens in the finite element model. The average calculation time is 20 times less if compared with the finite element model. In Fig. 17 the results of the proposed model are compared with the experimental tests. As observed in Section 3, specimens were not perfectly fixed in the cases. For this reason, they cannot be accurately modelled as fixed bar, but some horizontal springs must be imposed, as seen in Fig. 8 and as contemplated in the numerical model implemented in Abaqus [50], which is done in Section 3. Nonetheless, the proposed model assumes ends are fully fixed. Hence, Fig. 17 shows how the curves of the proposed model undergo higher average stresses at the same equivalent strain than the experimental curves. This effect is more marked as the slenderness of specimens is lower.

\section{Summary and conclusions}

An experimental campaign was carried out with Ni-Ti-type $12 \mathrm{~mm}$-diameter SMA bars in order to study instability in compression. Similar tests with steel bars were previously conducted to control the variables that can affect the experimental test and those that can affect the finite element model, which do not correspond to the material.

The finite element model was calibrated based on experimental results and it was used to perform a parametric study. The conclusions of this parametric study and the experimental results on the behavior of $\mathrm{Ni}-\mathrm{Ti}$ bars are the following: 


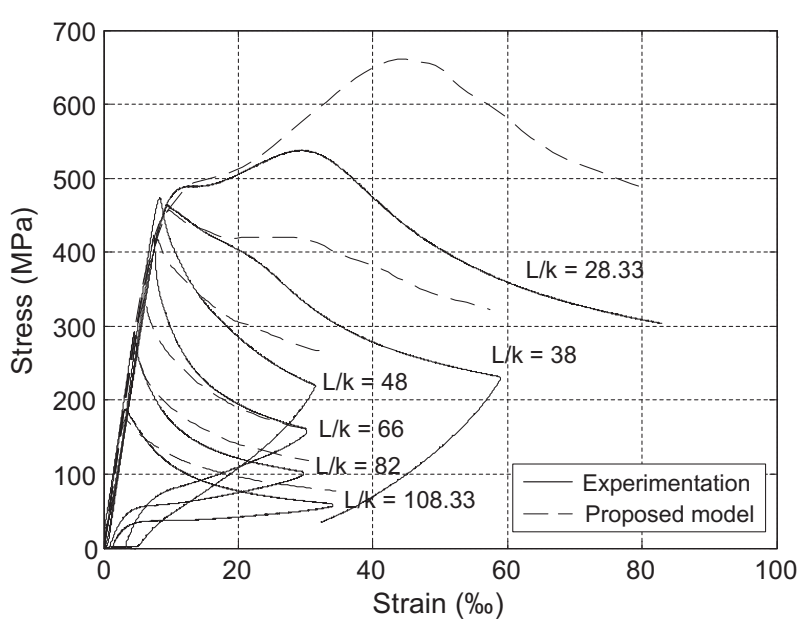

Fig. 17. Comparing the proposed model with the experimental results.
- For low slenderness levels, load can increase after the first instability point rather than decrease. The first instability point occurs when the bar fibers enter the martensitic transformation branch with the resulting decrease in the tangent elasticity modulus. After this, the load can rise as the martensitic transformation of the bar fibers finishes and the tangent elasticity modulus increases. Then the applied load decreases for a higher strain due to second-order effects. Thus, two instability points appear in low slenderness specimens and the martensitic elasticity modulus becomes very important.

- For high slenderness levels, the martensitic elasticity modulus is not important, although the austenitic elasticity modulus is. Also for high slendernesses, instability commences before the material leaves the initial linear regime. For this reason, and according to Euler Theory, the initial elasticity modulus marks the start of instability.

- Regarding asymmetry in tension-compression behavior in $\mathrm{Ni}-\mathrm{Ti}$ strains, the shorter martensitic transformation branch length under compression than in tension causes a less marked drop in the load applied on the branch after the instability point.

- Finally, regarding asymmetry in tension-compression behavior in stresses, the difference in stresses at the beginning and at the end of martensitic phase transformations is important for low slendernesses because, in such cases, instability commences when the section fibers enter the martensitic transformation phase.

An analytical model has been proposed to determine the monotonic constitutive average stress - equivalent strain relationship under compression for Ni-Ti bars, including the second order instability effects. This model is based on the bar energy equilibrium, and it is valid for Ni-Ti bars and those made of any other material. The novelty of the proposed model is that an average stress equivalent strain curve can be obtained for a material, including second order instability effects, without using more complex finite element models, on the basis of the fundamental constitutive curve of the material. The proposed analytical model has the following advantages in comparison with the finite element model: less sensitivity with regard to the size of discretization, decrease in calculation time, independence from the considered geometric imperfections and less convergence problems.

\section{Acknowledgments}

The model presented here is part of a research strand that is being undertaken within the Concrete Science and Technology
Institute (ICITECH) at the Universitat Politècnica de València (UPV). The authors are sincerely grateful to the Spanish Ministry of Economy and Competitiveness for the help it has provided through Project BIA2012-32645 and to the European Union for financial support obtained from FEDER funds. Besides, authors wish to thank Alberto Navarro Gómez and Oscar Sahuquillo Navarro for helping with material characterization.

\section{References}

[1] M. Branco, L. Guerreiro, K.K. Mahesh, F.M. Braz Fernandes, Effect of load cycling on the phase transformations in $\mathrm{Ni}$-Ti wires for civil engineering applications, Constr. Build. Mater. 36 (2012) 508-519, http://dx.doi.org/10.1016/ j.conbuildmat.2012.06.003.

[2] A. Cladera, B. Weber, C. Leinenbach, C. Czaderski, M. Shahverdi, M. Motavalli, Iron-based shape memory alloys for civil engineering structures: an overview, Constr. Build. Mater. 63 (2014) 281-293, http://dx.doi.org/10.1016/ j.conbuildmat.2014.04.032.

[3] H. Fang, M.B. Wong, Y. Bai, R. Luo, Effect of heating/cooling rates on the material properties of NiTi wires for civil structural applications, Constr. Build Mater. 101 (Part 1) (2015) 447-455, http://dx.doi.org/10.1016/ j.conbuildmat.2015.10.081.

[4] W. Sun, Seismic response control of high arch dams including contraction joint using nonlinear super-elastic SMA damper, Constr. Build. Mater. 25 (2011) 3762-3767, http://dx.doi.org/10.1016/j.conbuildmat.2011.04.013.

[5] A.H.M. Muntasir Billah, Alam M. Shahria, Seismic performance of concrete columns reinforced with hybrid shape memory alloy (SMA) and fiber reinforced polymer (FRP) bars, Constr. Build. Mater. 28 (2012) 730-742, http://dx.doi.org/10.1016/j.conbuildmat.2011.10.020.

[6] B. Gencturk, Y. Araki, T. Kusama, T. Omori, R. Kainuma, F. Medina, Loading rate and temperature dependency of superelastic $\mathrm{Cu}-\mathrm{Al}-\mathrm{Mn}$ alloys, Constr. Build Mater. $53 \quad$ (2014) 555-560, http://dx.doi.org/10.1016/ j.conbuildmat.2013.12.002.

[7] C. Qiu, S. Zhu, Characterization of cyclic properties of superelastic monocrystalline $\mathrm{Cu}-\mathrm{Al}-\mathrm{Be} \mathrm{SMA}$ wires for seismic applications, Constr. Build $\begin{array}{llll}\text { Mater. } & 72 & \text { (2014) 219-230, http://dx.doi.org/10.1016/ }\end{array}$ j.conbuildmat.2014.08.065.

[8] Y. Kuang, J. Ou, Self-repairing performance of concrete beams strengthened using superelastic SMA wires in combination with adhesives released from hollow fibers, Smart Mater. Struct. 17 (2008) 025020.

[9] Y. Kuang, J. Ou, Passive smart self-repairing concrete beams by using shape memory alloy wires and fibers containing adhesives, J. Cent. South Univ. Technol. 15 (2008) 411-417, http://dx.doi.org/10.1007/s11771-008-0077-9.

[10] C. Czaderski, M. Shahverdi, R. Brönnimann, C. Leinenbach, M. Motavalli, Feasibility of iron-based shape memory alloy strips for prestressed strengthening of concrete structures, Constr. Build. Mater. 56 (2014) 94-105, http://dx.doi.org/10.1016/j.conbuildmat.2014.01.069.

[11] Q. Chen, M. Shin, B. Andrawes, Experimental study of non-circular concrete elements actively confined with shape memory alloy wires, Constr. Build

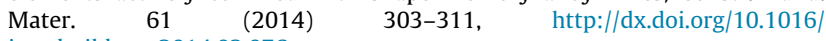
j.conbuildmat.2014.02.076.

[12] W.J. Lee, B. Weber, C. Leinenbach, Recovery stress formation in a restrained FeMn-Si-based shape memory alloy used for prestressing or mechanical joining, Constr. Build. Mater. 95 (2015) 600-610, http://dx.doi.org/10.1016/ j.conbuildmat.2015.07.098.

[13] M.K. Kim, D.J. Kim, Y.-S. Chung, E. Choi, Direct tensile behavior of shapememory-alloy fiber-reinforced cement composites, Constr. Build. Mater. 102 $\begin{array}{llll}\text { (Part 1) (2016) 462-470, http://dx.doi.org/10.1016/ } & \text { 1) }\end{array}$ j.conbuildmat.2015.11.015.

[14] M. Shahverdi, C. Czaderski, M. Motavalli, Iron-based shape memory alloys for prestressed near-surface mounted strengthening of reinforced concrete beams, Constr. Build. Mater. 112 (2016) 28-38, http://dx.doi.org/10.1016/ j.conbuildmat.2016.02.174.

[15] J. Osteraas, H. Krawinkler, The Mexico earthquake of September 19, 1985behavior of steel buildings, Earthquake Spectra 5 (1989) 51-88, http://dx.doi. org/10.1193/1.1585511.

[16] H. Kim, S. Goel, Seismic Evaluation and Upgrading of Braced Frame Structures for Potential Local Failures UMCEE 92-24, Dept. of Civil Engineering and Environmental Engineering, Univ. of Michigan, Ann Arbor, 1992.

[17] R. Tremblay, A. Filiatrault, P. Timler, M. Bruneau, Performance of stee structures during the 1994 Northridge earthquake, Can. J. Civil Eng. 22 (1995) 338-360.

[18] R. DesRoches, J. McCormick, M. Delemont, Cyclic properties of superelastic shape memory alloy wires and bars, J. Struct. Eng. ASCE 130 (2004) 38-46.

[19] A. Bekker, L.C. Brinson, Phase diagram based description of the hysteresis behavior of shape memory alloys, Acta Mater. 46 (1998) 3649-3665.

[20] K. Tanaka, F. Nishimura, T. Hayashi, H. Tobushi, C. Lexcellent, Phenomenological analysis on subloops and cyclic behavior in shape memory alloys under mechanical and/or thermal loads, Mech. Mater. 19 (1995) 281-292, http://dx.doi.org/10.1016/0167-6636(94)00038-I.

[21] Z. Bo, D.C. Lagoudas, Thermomechanical modeling of polycrystalline SMAs under cyclic loading, Part I: theoretical derivations, Int. J. Eng. Sci. 37 (1999) 1089-1140. 
[22] D.C. Lagoudas, Z. Bo, Thermomechanical modeling of polycrystalline SMAs under cyclic loading, Part II: material characterization and experimental results for a stable transformation cycle, Int. J. Eng. Sci. 37 (1999) 1141-1173.

[23] Z. Bo, D.C. Lagoudas, Thermomechanical modeling of polycrystalline SMAs under cyclic loading, Part III: evolution of plastic strains and two-way shape memory effect, Int. J. Eng. Sci. 37 (1999) 1175-1203.

[24] Z. Bo, D.C. Lagoudas, Thermomechanical modeling of polycrystalline SMAs under cyclic loading, Part IV: modeling of minor hysteresis loops, Int. J. Eng. Sci. 37 (1999) 1205-1249.

[25] A. Giuffrè, P.E. Pinto, Il comportamento del cemento armato per sollecitazioni cicliche di forte intensità, Giornale Del Genio Civile 5 (1970) 391-408.

[26] M. Menegotto, P.E. Pinto, Method of Analysis for Cyclically Loaded RC Frames Including Changes in Geometry and Non-elastic Behaviour of Elements Under Combined Normal Force and Bending. IABSE Congress Reports of the Working Commission, 1973 , p. 13.

[27] A. Gomes, J. Appleton, Nonlinear cyclic stress-strain relationship of reinforcing bars including buckling, Eng. Struct. 19 (1997) 822-826.

[28] R.P. Dhakal, K. Maekawa, Path-dependent cyclic stress-strain relationship of reinforcing bar including buckling, Eng. Struct. 24 (2002) 1383-1396.

[29] L.M. Massone, D. Moroder, Buckling modeling of reinforcing bars with imperfections, Eng. Struct. 31 (2009) 758-767, http://dx.doi.org/10.1016/j. engstruct.2008.11.019.

[30] L.M. Massone, E.E. López, Modeling of reinforcement global buckling in RC elements, Eng. Struct. 59 (2014) 484-494, http://dx.doi.org/10.1016/j. engstruct.2013.11.015.

[31] J.B. Mander, University of Canterbury. Seismic design of bridge piers, 1983

[32] J.B. Mander, F.D. Panthaki, A. Kasalanati, Low-cycle fatigue behavior of reinforcing steel, J. Mater. Civil Eng. 6 (1994) 453-468.

[33] G. Monti, C. Nuti, Nonlinear cyclic behavior of reinforcing bars including buckling, J. Struct. Eng. 118 (1992) 3268-3284.

[34] M.E. Rodriguez, J.C. Botero, J. Villa, Cyclic stress-strain behavior of reinforcing steel including effect of buckling, J. Struct. Eng. 125 (1999) 605-612.

[35] O. Bayrak, S.A. Sheikh, Plastic hinge analysis, J. Struct. Eng. 127 (2001) 10921100.

[36] S. Bae, A.M. Mieses, O. Bayrak, Inelastic buckling of reinforcing bars, J. Struct. Eng. 131 (2005) 314-321, http://dx.doi.org/10.1061/(ASCE)0733-9445(2005) 131:2(314).

[37] M.A. Rahman, J. Qiu, J. Tani, Buckling and postbuckling characteristics of the superelastic SMA columns, Int. J. Solids Struct. 38 (2001) 9253-9265.

[38] M.A. Rahman, J. Tani, Postbuckling characteristics of the short superelastic shape memory alloy columns-experiment and quantitative analysis, Appl. Mech. Eng. 11 (2006) 941.

[39] A.A. Movchan, I.A. Movchan, L.G. Sil'chenko, Effect of structural transformation and deformation nonlinearity on the stability of a shape memory alloy rod,
Mech. Solids $45 \quad$ (2010) 876-884, http://dx.doi.org/10.3103/ S0025654410060117.

[40] A.A. Movchan, L.G. Sil'chenko, T.L. Sil'chenko, Taking account of the martensite inelasticity in the reverse phase transformation in shape memory alloys, Mech. Solids 46 (2011) 194-203, http://dx.doi.org/10.3103/S0025654411020075.

[41] F. Richter, O. Kastner, G. Eggeler, Finite-element simulation of the antibuckling-effect of a shape memory alloy bar, J. Mater. Eng. Perform. 20 (2011) 719-730, http://dx.doi.org/10.1007/s11665-010-9797-8.

[42] Y. Urushiyama, D. Lewinnek, J. Qiu, J. Tani, Buckling of shape memory alloy columns (Buckling of Curved Column and Twinning Deformation Effect), JSME Int. J., Ser A 46 (2003) 60-67.

[43] A.H.M.M. Billah, Alam M. Shahria, Plastic hinge length of shape memory alloy (SMA) reinforced concrete bridge pier, Eng. Struct. 117 (2016) 321-331, http:// dx.doi.org/10.1016/j.engstruct.2016.02.050.

[44] A.H.M. Muntasir Billah, M.S. Alam, Bond behavior of smooth and sand-coated shape memory alloy (SMA) rebar in concrete, Structures 5 (2016) 186-195, http://dx.doi.org/10.1016/j.istruc.2015.11.005.

[45] B. Mas, A. Cladera, C. Ribas, Experimental study on concrete beams reinforced with pseudoelastic $\mathrm{Ni}-\mathrm{Ti}$ continuous rectangular spiral reinforcement failing in shear, Eng. Struct. 127 (2016) 759-768, http://dx.doi.org/10.1016/j. engstruct.2016.09.022.

[46] Wai-Fah Chen, E.M. Lui, Structural Stability: Theory and Implementation, PTR Prentice Hall, 1987.

[47] AENOR, Spanish Association for Standards and Certification. UNE-EN ISO 68921:2009. Metallic materials. Tensile testing. Part 1: Method of test at ambient temperature, 2002.

[48] F. Auricchio, E. Sacco, A superelastic shape-memory-alloy beam model, J. Intell. Mater. Syst. Struct. 8 (1997) 489-501, http://dx.doi.org/10.1177/ $1045389 \times 9700800602$.

[49] L. Orgéas, D. Favier, Non-Symmetric Tension-Compression Behaviour of NiTi Alloy. J. Phys. IV 1995;05:C8-605-C8-610. doi:10.1051/jp4/199558605.

[50] Dassault Systèmes Simulia Corp. ABAQUS 6.13. Abaqus analysis user's manual, 2013.

[51] F. Auricchio, R.L. Taylor, Shape-memory alloys: modelling and numerical simulations of the finite-strain superelastic behavior, Comput. Methods Appl. Mech. Eng. 143 (1997) 175-194.

[52] F. Auricchio, R.L. Taylor, Shape-memory alloys: macromodelling and numerical simulations of the superelastic behavior, Comput. Methods Appl. Mech. Eng. 146 (1997) 281-312.

[53] R.P. Dhakal, K. Maekawa, Reinforcement stability and fracture of cover concrete in reinforced concrete members, J. Struct. Eng. 128 (2002) 12531262.

[54] M.M. Talaat, K.M. Mosalam, Computational modeling of progressive collapse in reinforced concrete frame structures. ProQuest, 2007. 